\title{
A Modified Stroop Task With Sexual Offenders: Replication of a Study \\ by
}

Shelley A. Price

\author{
A thesis submitted to \\ the Faculty of Graduate Studies and Research \\ in partial fulfillment of the requirements \\ for the degree of \\ (Master of Arts) \\ Department of Psychology \\ Carleton University \\ Ottawa, Ontario
}

January 2006 


$\begin{array}{ll}\begin{array}{l}\text { Library and } \\ \text { Archives Canada }\end{array} & \begin{array}{l}\text { Bibliothèque et } \\ \text { Archives Canada }\end{array} \\ \begin{array}{l}\text { Published Heritage } \\ \text { Branch }\end{array} & \begin{array}{l}\text { Direction du } \\ \text { Patrimoine de l'édition }\end{array} \\ \begin{array}{l}\text { 395 Wellington Street } \\ \text { Ottawa ON K1A ON4 }\end{array} & \begin{array}{l}\text { 395, rue Wellington } \\ \text { Ottawa ON K1A ON4 } \\ \text { Canada }\end{array}\end{array}$

Your file Votre référence ISBN: 978-0-494-16439-6 Our file Notre référence ISBN: 978-0-494-16439-6

NOTICE:

The author has granted a nonexclusive license allowing Library and Archives Canada to reproduce, publish, archive, preserve, conserve, communicate to the public by telecommunication or on the Internet, loan, distribute and sell theses worldwide, for commercial or noncommercial purposes, in microform, paper, electronic and/or any other formats.

The author retains copyright ownership and moral rights in this thesis. Neither the thesis nor substantial extracts from it may be printed or otherwise reproduced without the author's permission.
AVIS:

L'auteur a accordé une licence non exclusive permettant à la Bibliothèque et Archives Canada de reproduire, publier, archiver, sauvegarder, conserver, transmettre au public par télécommunication ou par l'Internet, prêter, distribuer et vendre des thèses partout dans le monde, à des fins commerciales ou autres, sur support microforme, papier, électronique et/ou autres formats.

L'auteur conserve la propriété du droit d'auteur et des droits moraux qui protège cette thèse. $\mathrm{Ni}$ la thèse ni des extraits substantiels de celle-ci ne doivent être imprimés ou autrement reproduits sans son autorisation.
In compliance with the Canadian

Privacy Act some supporting forms may have been removed from this thesis.

While these forms may be included in the document page count, their removal does not represent any loss of content from the thesis.
Conformément à la loi canadienne sur la protection de la vie privée, quelques formulaires secondaires ont été enlevés de cette thèse.

Bien que ces formulaires aient inclus dans la pagination, il n'y aura aucun contenu manquant.

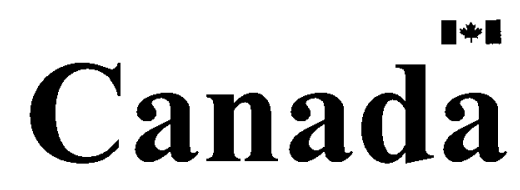




\begin{abstract}
Cognitive Behavioural treatment of sexual offenders assumes that sexual offenders are motivated by deviant attitudes, perceptions and values. Although aspects of deviant schema can be assessed by questionnaires, self-report measures are limited by the respondent's willingness to be forthright and by the fact that these cognitive processes typically occur quickly, revealing signs of automaticity. Recent research by Smith and Waterman (2004) has suggested that the deviant schema of sexual offenders could be assessed using a version of the Stroop colour-naming task. Long latency periods to sexual colour words imply a longer information-processing route and evidence of preestablished (deviant) sexual cognitive schema. An important feature of Stroop techniques is that they have the potential of reducing the fakeability and social desirability concerns associated with self-report measures. The current study replicates and extends Smith and Waterman's results using a sample of sexual offenders and non-sexual violent offenders. The current study also extends Smith and Waterman's research by including new word lists intended to differentiate rapist and child molesters. Significant differences were yielded between rapists and the community sample for sexual word bias scores, and no significant differences were found with the addition of the new word lists in experiment 2. The results in this study were weaker than those found by Smith and Waterman, but similar patterns were evident. The Stroop task may hold promise in measuring the attitudes and cognitive processes related to offending, but research is still preliminary in this field, and further research is required to determine which word stimuli will produce the desired results of being able to differentiate between offender samples.
\end{abstract}


I would like to thank my family and friends for always providing me with the support that was required to complete this difficult step. Mom, you have always brought me sunshine, love, and sanity. I could never ask for more. Dad, you have always been able to remind me of how important finishing and advancing in school and life is. James, it was nice to see how much you believed in me, and how much you hoped all the best for me. Oliver and Cleo, always by my side.

Dr. Andrews, thank you for agreeing to take on this project, even when you were surprised to hear of the ancient tools I would be using to complete this project! I also thank you for your help with administrative stuff (as it is always so much fun!), and for your interest in what may result from this study.

Karl, you have taught me how to strive for something that I want, and have offered me so much help and guidance over the years that I am not exactly sure how to thank you. Your patience and support have helped me through many steps of this journey and I thank you very much. 


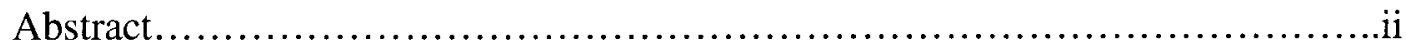

Acknowledgements...................................................

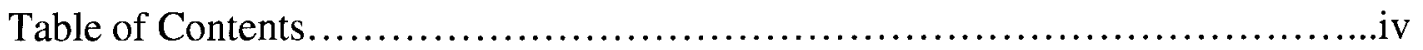

List of Tables.........................................................

List of Figures...................................................... vii

List of Appendices......................................................... viii

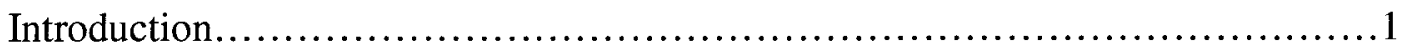

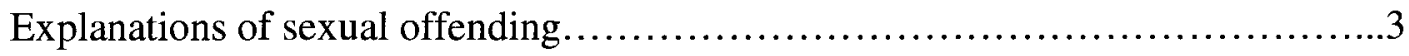

Schemas and cognitive distortions......................................... 14

Measurement of deviant sexual interests.................................... 17

The emotional Stroop task...............................................25

Stroop and alcohol................................................27

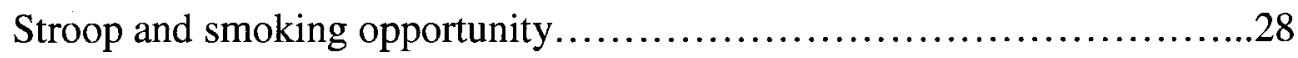

Stroop and phobia research.....................................29

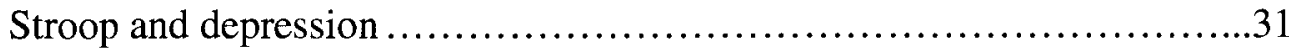

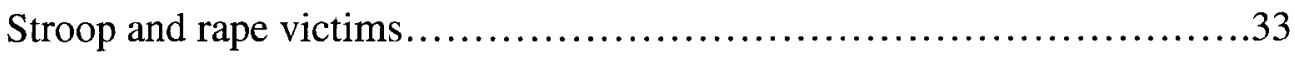

General Stroop findings..........................................33

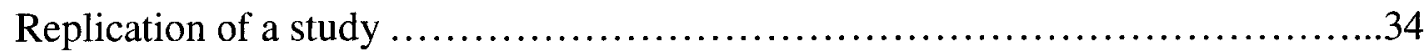

The present study....................................................

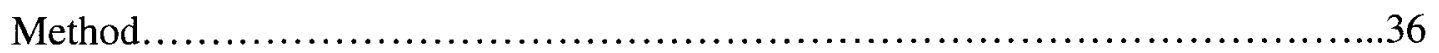

Participants................................................... 36

Inclusion/exclusion criteria...................................37 
Apparatus/Materials.............................................. 38

Data management and confidentiality........................40

Design and Procedures.........................................40

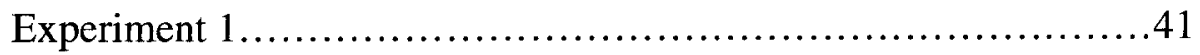

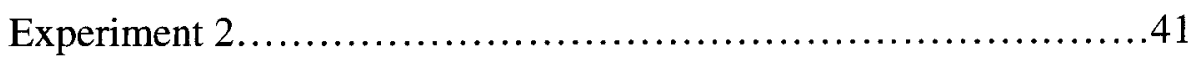

Hypotheses.............................................43

Analyses.................................................43

Results ............................................................. 46

Discussion......................................................... 52

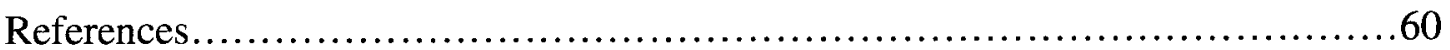




\section{List of Tables}

Table 1: Characteristics of Sexual Abuse Experiences..........................

Table 2: Summary of the Four Pathways Proposed by the Self-Regulation Model...11

Table 3: Cronbach's Coefficient Alpha Correlations for VRT Slide Categories......22

Table 4: Demographic, Mean Responses to Questionnaires, and Rejected

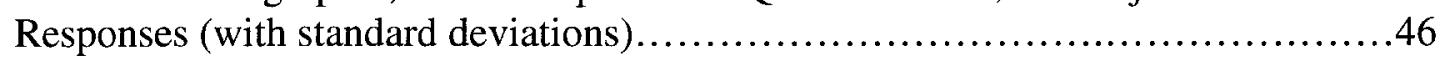

Table 5: Participant Mean Response Times in Milliseconds, ms, and Bias Scores

(With Standard Deviations in Parentheses) for Experiment 1 Stroop Task............48

Table 6: Participant Mean Response Times in Milliseconds, ms, and Bias Scores

(With Standard Deviations in Parentheses) for the Experiment 2 Stroop Task.......49

Table 7: Mean Responses to Self-Report Sexual Questionnaires, With

Standard Deviations..................................................... 51 


\section{List of Figures}

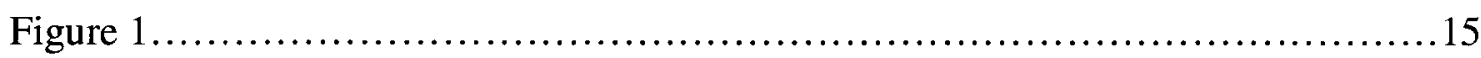




\section{List of Appendices}

Appendix A.........................................................69

Appendix B............................................................ 72

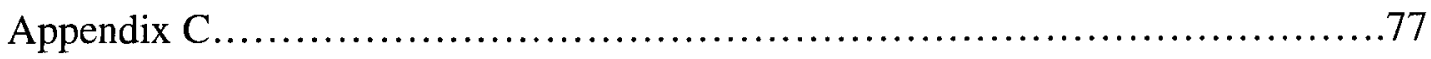

Appendix D..........................................................

Appendix E........................................................... 86

Appendix F........................................................ 93

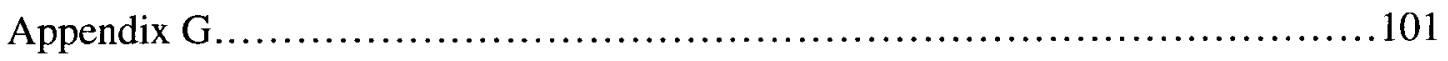

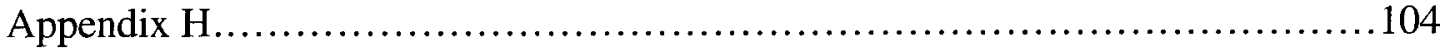


Measuring the Deviant Schema of Sexual Offenders: A Stroop Replication Study Shelley Price

Sexual offenders elicit a great deal of public fear, and uproars often follow announcements of their release. It is difficult to obtain accurate rates of sexual victimization because many victims do not report sexual attacks due to embarrassment and fear. Finkelhor, Hotaling, Lewis and Smith (1990) reported on the Los Angeles Times sexual victimization poll and found that out of 2,626 respondents $(1,145$ male respondents and 1,481 female respondents), $27 \%$ of females and $16 \%$ of males had been victims of sexual assault at some point prior to the survey having taken place. The results indicated that the median age of victimization was 9.9 years for boys, and 9.6 years old for girls. Additionally, boys were more likely than girls to be victimized by strangers, and girls more likely to be victimized by family members (See Table 1).

In 2002, National Crime Victimization Survey (NCVS) data reported annual rates of rape and sexual assault to be 1.1 per 1,000 persons ages 12 and older, and in 2003 this rate slightly declined to 0.8 per 1,000 persons aged 12 or more (Bureau of Justice Statistics, 2003). In a meta-analysis examining the self-reported victimization rates of college males and females, Rind, Tromovitch, and Bauserman (1998), found that $13 \%$ $(\mathrm{N}=506)$ of the males and $16 \%(\mathrm{~N}=2,172)$ of the females had reported being victims of child sexual abuse to the extent of having intercourse with their predator. Canadian victimization rates in 1999 show that 21 out of 1,000 (2.1\%) Canadians aged 15 or older were victims of sexual assault in the previous year, an increase from $1.6 \%$ in 1993 (Public Safety and Emergency Preparedness Canada, 2004). 
Table 1.

Characteristics of Sexual Abuse Experiences (From Finkelhor et al., 1990)

\begin{tabular}{lcc}
\hline Characteristic & Men $(\mathrm{N}=169)$ & Women $(\mathrm{N}=416)$ \\
& $\%$ & $\%$ \\
\hline Gender of perpetrator & 83 & 98 \\
Male & 17 & 1 \\
Female & & 4 \\
Age difference & 3 & 19 \\
3 years or less & 34 & 72 \\
4-10 years & 61 & 5 \\
10 years or more & 2 & \\
Don't know & & 21 \\
Relationship to perpetrator & 40 & 33 \\
Stranger & 31 & 8 \\
Known & 13 & 5 \\
Friend & 5 & 14 \\
Cousin & 5 & 2 \\
Uncle/aunt & 1 & 2 \\
Sibling & 0 & 3 \\
Grandparent & 0 & 3 \\
Stepparent & 0 & 9 \\
Natural/parent & 5 & 49 \\
Other & 49 & \\
Authority figure & & \\
\hline
\end{tabular}

The proportion of perpetrators in the general population is even more difficult to estimate. Marshall (1997a) reported that approximately $1 \%-2 \%$ of the U.K. male population will eventually be convicted of a sexual crime. In the United States, it is estimated that 234,000 convicted sex offenders are within the criminal justice system, either imprisoned or under conditional release (Stalans, 2004). In a national survey, Finkelhor and Lewis (1988) found that $17 \%$ of males questioned admitted to acts of child molestation.

Using a sample of college men, Osland, Fitch, and Willis (1996) found that $34 \%$ of the 159 participants reported some tendency to rape and/or force sexual relations, along with greater beliefs in traditional roles of women, and greater acceptance of rape 
myths. Rubenzahl and Corcoran (1998) examined rates of self-reported acquaintance rapes in a college sample and found that $24 \%(n=25)$ of their respondents admitted to being perpetrators of acquaintance rape. Thirty-four of their respondents were classified as sexual aggressors based on their responses to the Sexual Experiences Survey (SES), and admitting to the use of some form of coercion to gain sexual access with a victim.

\section{Explanations of Sexual Offending}

Past research has offered several potential explanations as to why individuals sexually offend. Finkelhor (1986) notes that many single-factor theories have surfaced but they do not provide satisfactory explanations for child sexual abuse. For example, one common theory attributes child sexual abuse to having once been a victim of sexual abuse. Finkelhor (1986) notes that the difficulty with single-factor theories is their inability to generalize across all child molesters. For example, a history of sexual victimization is found for approximately $30 \%$ of child molesters (Hanson \& Slater, 1988).

Additional problems with single-factor theories is that they may create unfounded confidence that prevent further inquiry. Not only are there downfalls to trusting singlefactor theories for the researcher, but depending on a single answer (such as previous sexual victimization) may instil unwarranted fear in new victims, with the thought that they might one day become child molesters themselves (Finkelhor, 1986).

Rather than using single-factor theories to explain child molesting, Finkelhor (1986) proposes a four-factor model: emotional congruence, sexual arousal, blockage, and disinhibition. First, emotional congruence refers to immature emotional development of the adult that leaves the offender feeling more satisfied by identifying with children as 
opposed to relating to adults. Arousal, the second factor identified by Finkelhor refers to the capacity to become sexually aroused to children. The arousal cannot be interrupted by a separate outlet (that would be considered more socially acceptable) in order for the adult to perform sexual acts with children. The third factor, blockage, assumes that the offender lacks sexual access to appropriate partners (i.e., adults). Finally, disinhibition needs to be present for the offender to perform sexual acts with children. Offenders know that molesting children is socially disapproved of, so they must find ways to overcome such barriers through, for example, rationalizations, substance use and desensitization. Taking all four factors into account, an active pedophile may first find themselves more emotionally satisfied through relationships with children as opposed to adults, is aroused by children, lacks access to sexual relations with adults, and lacks strong inhibitions for committing the offence.

Finkelhor (1982) also suggests that certain family characteristics are present among children at risk for sexual victimization: isolation and male domination (or patriarchal families). Finkelhor (1982) suggests that families where child sexual abuse occurs might keep themselves isolated from other families, thereby reducing the chances of the abuse being discovered. Further, abuse might occur in patriarchal families where the children and wife/mother are too afraid to report sexual abuse, and are simply taught to do what they are told. Additionally, Finkelhor (1982) suggests that a shift in family structures might be responsible for an increased risk of child sexual victimization. The presence of more parental figures has the potential to introduce more sexual abusers. Finkelhor (1982) attributes some cases of sexual abuse to changes in how we as a society view sexual relations. For example, being more open to discuss and view sexual 
materials may contribute in part to confusion about sexual boundaries and appropriate sexual conduct.

Finkelhor et al. (1990) identify several risk factors for sexual victimization such as an unhappy family life, dwelling without one natural parent, and for women, receiving inadequate sexual education. In a review of the research, Finkelhor (1993) notes that there are no family structure "markers" that would either confirm or refute the presence of sexual abuse. In other words, there is not one clear group of individuals that are more prone to being sexually victimized through an examination of their family characteristics. Additionally, the author refutes notions that indicators of social class, such as education, income and occupational status, can be used to identify the presence of sexual abuse. Finkelhor (1993) does note that children from lower social class are disproportionately represented as victims of sexual abuse, and that the presence of a stepfather, an absent mother, poor parenting, punitive parenting, conflicting parental relationship and paternal violence are all risk factors for sexual victimization.

Marshall and Barbaree (1990) have adopted a different approach in emphasizing the role of learning experiences, sociocultural experiences and biological processes in the development of sexually abusive behaviours. Marshall and Barbaree (1990) mainly refer to the behaviours of rapists, but do note that much of their theory may be applicable to non-contact sexual offenders such as exhibitionists, as well as pedophilic behaviours. The authors begin their explanation by identifying the need for individuals to distinguish between innate sexual and aggressive instincts. Marshall and Barbaree (1990) stress that although all individuals inherently possess sexual and aggression instincts, some are not provided with the means to separate the two, and that it is the fusing of these two instincts 
that result in sexual offending. The focus on biological explanations for sexual behaviours ends once the individual has established a learning pattern. Additionally, biological factors, such as level of hormones, will influence not only the individual's learning patterns, but also the difficulty separating sexual and aggression instincts. It is the task of the individual to be able to distinguish between these two instincts and in turn inhibit aggressive behaviours when sexual instincts are active.

Marshall and Barbaree (1990) also emphasize learning and environmental factors in the development of sexual behaviours: specifically, childhood experiences, sociocultural context and transitory situational factors. First, childhood experiences are crucial in shaping the separation of sexual and aggressive instincts. For example, violent parenting styles, frequent and severe punishments inconsistent with their behaviours, sexual abuse, alcoholic parents, and criminal parents are common factors reported by sexual offenders. From the point of view of Marshall and Barbaree (1990), it is then not surprising that sexual offenders display difficulties in separating their sexual instincts from their aggressive instincts because the behaviours being modeled at a crucial point of childhood development do not reflect a distinct separation of these instincts. Instead, the offender is taught early on that the use of aggression to acquire what they want is acceptable. The authors stress that this is by no means an excuse for the behaviours of sexual offenders, as many individuals experience the same types of abuse and do not become sexual offenders, but it is important to note that childhood experiences are essential in the proper development of biological instincts. Additionally, Marshall and Barbaree (1990) emphasize the role of self-esteem, encouragement, and prosocial parenting in the appropriate development of intimate relationships and prosocial 
behaviours. For example, it is expected that if a child grows up in a largely prosocial environment where they are encouraged frequently, and the parents model appropriate behaviours, then the development of relationships with appropriate individuals are more easily obtained. Without the proper development of social interactions with peers, the offender may experience emotional loneliness, anxiety within social situations for which they lack the necessary skills, feelings of alienation and inadequacy, and anger towards those that caused them to feel this way. Such social impediments could translate into sexual offending behaviours.

Once the individual has the opportunity to explore beyond the family context, sociocultural factors add to the development of proper sexual inhibitions. Generally, Marshall and Barbaree (1990) list interpersonal violence, male dominance and negative attitudes towards females as major contributors of sexual offending. For example, societies that condone violence against women and support male dominance had higher rates of sexual assaults against women than societies that did not. The media is another sociocultural factor influencing the development of proper sexual instincts. For example, portrayals of men being rewarded for aggressive sexual acts against women on television might be processed differently by someone that has lacked proper guidance than by someone that has primarily experienced prosocial parenting styles. Vulnerability to certain influences is what distinguishes the sexual offender from the sexually prosocial individual in this theory.

Finally, Marshall and Barbaree (1990) note that certain situational factors may disinhibit sexually appropriate behaviours and ease the path into sexual offending such as alcohol, stress, anger, hostility, and prior arousal. For example, a sexual offence may be 
more likely to occur when the offender is under the influence of alcohol and has been humiliated and angered. The availability of a victim would then make it easier for the sexual act to occur.

As previously mentioned, Marshall and Barbaree (1990) focus most of their theory on rapists, but do note throughout that the sexual offences can be against children or non-contact offences. For example, the lack of prosocial parenting may be similar, rendering the individual more drawn towards sexually deviant material (such as pornography involving children), and perhaps more comfortable developing emotional bonds with children (still rendering the offender inadequate in adult intimate relationships). The fantasies that are eventually acted out would involve different victims choices and different offending behaviours, but the pedophile is still influenced by biological factors, learning experiences and sociocultural factors.

Quinsey and Lalumière (1995) follow an evolutionary approach to the explanation of sexual preferences and sexual experiences. The authors view sexual behaviours as satisfying the human's need to reproduce, and carry on the genes passed on by their ancestors. The problem that everyone is faced with is survival and reproduction within the environments that we are placed in. The authors suggest that males' ability to reproduce is limited to the availability of women, and women's reproductive abilities are limited by the number of children they are able to produce and the limited amount of time that they are able to reproduce for. Therefore, sexual coercion (such as rape) may be explained as a male's attempt at adapting and obtaining a female to reproduce his genes. For example, a male lacking access to women may turn to coercion as a method of ensuring that his ancestral genes continue into further generations. Although the main 
goal is to reproduce, this does not necessarily need to be the only driving force for sexual coercion. The male may be driven by anger or power, but the goal to reproduce is still present. The use of coercion is seen as an adaptive mating strategy. Child molestation is explained as a maladaptation in brain modules that would normally develop to prefer females in their most maximal reproductive age range. Additionally, homosexuality is seen as an abnormal adaptation and as a mental disorder because this preference does not follow the 'normal' path of evolutionary reproduction. Homosexuals are also seen to have underdeveloped masculinization of the brain. Incest is explained as a tendency to take advantage of mating opportunities paired with the failure to properly develop sexual inhibitions (or avoidance) against sexual relations with family members. Sexual deviance according to Quinsey and Lalumière (1995) is therefore explained by some sort of mental disorder, maladaptation of the brain, or under-developed brain module that inhibits the offender from following the natural evolutionary pathway, and increase the representation of their ancestors.

Ward et al. (2004) describe sexual offending behaviours as occurring through a pathway of behaviours. There are nine phases in their self-regulation model of the sexual offence pathway. In phase one a crucial life event occurs and due to previously established patterns of interpretation within the offender, the assessment of the life event activate the potential to sexually offend. For example, the presentation of divorce papers to a man that has distrust for women could activate scripts within the offender that aid to justify and rationalize sexually assaultive behaviours. Previously established goals and patterns of interpretation influence what information is attended to and when new information arises that would contradict their goals, the new information is also 
interpreted selectively to reflect the offender's interpersonal goals. Information that challenges the offender's interpersonal goals will be re-shaped to fit their automatic process of interpretation (Hudson, Ward \& McCormack, 1999; Ward et al., 2004).

In phase two, the offender experiences the desire to sexually offend, deviant sexual arousal and fantasies. Ward et al. (2004) note that it is the critical life event that occurs to trigger the sexually deviant desires and fantasies and internal and external cues also exist to further trigger fantasies and desires for sexual offending. Ward et al. (2004) note that in this stage certain 'offence scripts' develop or already exist within the offender's cognitions that allow for the offender's sexually abusive behaviours to emerge. For example, a script might include means of obtaining access to victims, methods of acting out sexual assaults, and methods of fleeing the scene once the act has been completed. The scripts become stronger and more automatic, and perhaps unconscious with time. The difficulty that arises with almost automatic scripts is that when high-risk situations arise, it may be difficult to refrain from following previously established offending scripts.

Following a major life event that triggers desires for deviant sex or activities, Ward et al. (2004) propose that offence related goals are established. In this phase, the offender decides what should be done about the fantasies that were contemplated. The offender decides whether to approach or avoid offending behaviour. If the offender decides to approach the feelings and desires to offend sexually, he proceeds towards a strategy to carry out the behaviour. The authors suggest that four offence pathways exist that propel the offender to either offend or relapse (see Table 2), and the pathway may be taken automatically (because pre-existing scripts exist) or may be a decision consciously 
made by the offender. In phase five, contact with the victim or potential victim occurs and a high-risk situation is entered in to. Planning has been completed in the previous stage and appraisal is the key behaviour in stage five. If the offender's original goal was to avoid sexually offending behaviours, negative feelings may encompass the failure to abstain, and may additionally cue previously established scripts to sexually offend and approach pathways. Conflicting goals and the need for immediate gratification might be present in this stage.

Table 2

Summary of the four pathways proposed by the self-regulation model

\begin{tabular}{|c|c|c|}
\hline Pathway & Self-regulatory style & Description \\
\hline Avoidant-passive & Under-regulation & $\begin{array}{l}\text { Desire to avoid sexual } \\
\text { offending but lacking the } \\
\text { coping skills to prevent it } \\
\text { from happening }\end{array}$ \\
\hline Avoidant-active & Mis-regulation & $\begin{array}{l}\text { Direct attempt to control } \\
\text { deviant thoughts and } \\
\text { fantasies but use of } \\
\text { ineffective or } \\
\text { counterproductive strategies }\end{array}$ \\
\hline Approach-automatic & Under-regulation & $\begin{array}{l}\text { Overlearned sexual scripts } \\
\text { for offending, impulsive } \\
\text { and poorly planned } \\
\text { behaviour }\end{array}$ \\
\hline Approach-explicit & Effective-regulation & $\begin{array}{l}\text { Desire to sexually offend } \\
\text { and the use of careful } \\
\text { planning to execute } \\
\text { offences, harmful goals } \\
\text { concerning sexual offending }\end{array}$ \\
\hline
\end{tabular}

(From Ward et al., 2004, pp.38)

Ward et al (2004) call stage six the "lapse" stage, where previous avoidant goals turn into approach goals and the intention to sexually offend is truly established. The offender no longer struggles with the potential consequences of their actions but rather, is encompassed by the need to obtain sexual gratification. Additionally, this stage allows 
the offender to forget for the time being the conflicting feelings and may return to avoidance goals once the offence is complete. Offenders who originally have approach goals will have no problem continuing along that pathway.

Phase seven is where the sexual offence occurs. The authors describe three subtypes illustrating the offender's perception towards their victim: self-focus (the offender's needs are dominant), victim focus (the victim is "cared" for) and mutual focus (a relationship is portrayed as present). Previously established goals, and schema will reflect in the offence style. In phase eight, a 'post offence evaluation' is conducted and the offender may exhibit feelings of failure and negative affect towards the offence that took place. If the offender attributes the offence to uncontrollable causes, further offending behaviours may be likely. If, however, the offender's original goals were approach oriented, then positive feelings would accompany the accomplishment of these goals.

Finally, in stage nine, attitudes towards future offending are contemplated. Here the offender decides again what types of sexual goals are important and those that follow approach pathways may continue through the cycle again in the same manner. Offenders may also decide to adopt an avoidant pathway and decide not to sexually offend again. The cycle presented by Ward et al. (2004) may occur rather quickly, or could take a long period of time to complete.

All four theories just described relate to deviant sexual behaviour. It is therefore necessary, for the purpose of this paper, to define several terms that will be used throughout. First, sexual interests will refer to the sexual behaviours or ideas that an individual attends to. Sexual interests are psychologically based in that each individual 
possesses cognitive ideas, beliefs, or preferences relating to what they find attractive, sexually stimulating, or significant for sexual arousal to occur. Sexual interests then may be thought of as thoughts, ideas, beliefs, feelings or perceptions relating to sexual behaviours and accepted by the individual as sexually stimulating or arousing. Sexual arousal, on the other hand, relates to the physiological reactions that occur when sexual interests are being pursued.

The focus of this paper is not on sexual interests and arousal alone, but on deviant sexual interests and deviant sexual arousal. Sexual interests become deviant when the behaviours are illegal. For example, in Canada, when an adult has sexual contact with an individual younger than 14 years old, and the offender is at least two years older than the victim, it is considered illegal (CCC: s. 150.1 (2)(b)). Additional illegal sexual acts include sexual advances or behaviours that are obtained through the use of force, without the victim's consent. In addition to illegal sexual acts, deviant sexual interests may include rare or unusual sexual behaviours, such as fetishism.

In all the theories reviewed, deviant sexual interest was considered an important contributor to sexual offending. Deviant sexual interests are common among sexual offenders (Lalumière \& Quinsey, 1994; Marshall, 1997b), and sexual offenders holding deviant sexual interests are more likely to recidivate than other sexual offenders (Hanson \& Bussière, 1998; Hanson \& Morton-Bourgon, 2004). Consequently, advances in the understanding and assessment of deviant sexual interest have considerable potential for improving the assessment and management of sexual offenders.

There are two important assumptions in this paper with respect to deviant sexual interests: (1) deviant sexual interests have a cognitive component, and (2) an 
understanding of these cognitive processes are essential to understanding the development and maintenance of deviant sexual interests. Although alternate assumptions are possible, the aim of this study is to explore the cognitive processing of deviant sexual interests to gain insight into how they may be developed and maintained. Before examining the cognitive processes associated with deviant sexual interests, it is worth considering cognitive processes more generally.

\section{Schemas and Cognitive Distortions}

According to Piaget, cognitive functioning is comprised of structures and functions (see Figure 1). Structures act as roadmaps for information, and guide the individual through the means and end of behaviour. Structures may change systematically as new information is processed. Functions are inherent methods of processing incoming information and remain unchanged. Piaget describes two types of functions: organization and adaptation. Inherently, the individual will try to organize incoming information into existing structures, and if it does not fit existing structures, adaptation will take place (Phillips, 1969).

For Piaget, the mind is made up of cognitive structures called schema or schemas (structures). Intelligence allows an organism to adapt to its environment, while schemata allow information to be organized and function to help individuals cope with or explain some aspect of experience. To Piaget, schemata (plural for schema) are structural units that form a framework onto which incoming sensory data can fit, and it is continually changing to better assimilate those data. Schemata then, come to act as roadmaps or guides for different situations or experiences. The more we use a particular schema, or behave a certain way, the more automatic our processing becomes. The earliest schemas 
are simple, but are adaptable and become more complex with experience. Information that is processed is categorized and clustered with other cognitions and schemata containing related materials (Shaffer, 1999).

Figure 1

Piaget's Theory (Phillips, 1969)

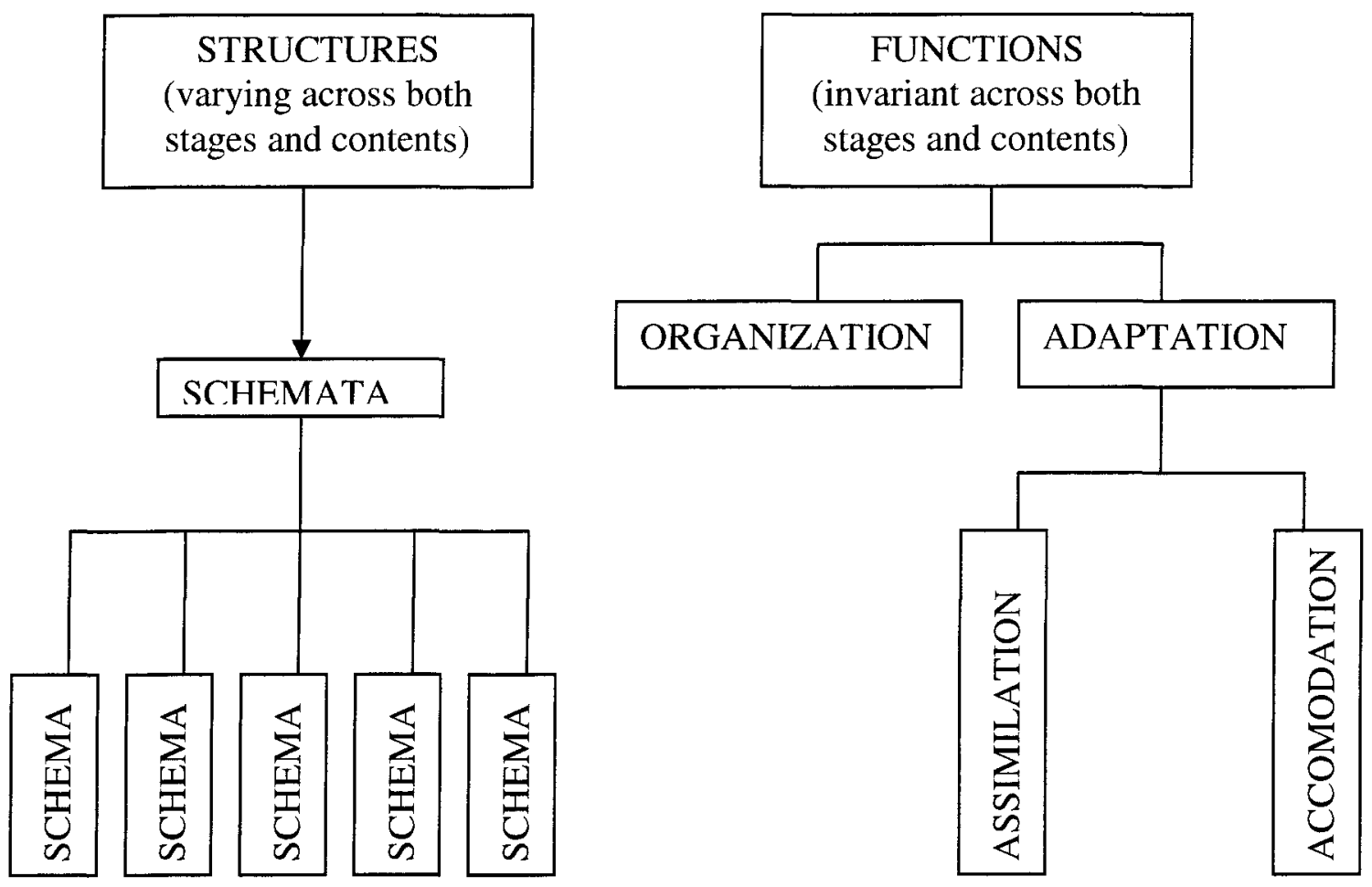

Piaget believed that one goal is central to all intellectual activities: to produce a balance between one's cognitions and their surrounding environment. When a balance is not present, disequilibrium is reached. Disequilibrium is a contradiction between what the individual knows and what the facts are. When disequilibrium is present, the individual will use one of two methods (functions) of returning back to a balanced, harmonious state: assimilation or accommodation (Phillips, 1969). 
Assimilation is defined as incorporating something from the environment with previously established mechanisms, or cognitions. Information is then categorized and clustered with other cognitions that contain related materials. Therefore, assimilation is the grouping of related materials, and new experiences are interpreted in terms of our current cognitive structures (Phillips, 1969).

Accommodation, on the other hand, is the correction of information that is already possessed, or the alteration of existing schemas so that they provide a better explanation. For example, we learn at some point that objects remain the same object even when different angles are experienced. Therefore, a cat will remain a cat, no matter what angle we view it from, but the original schema representing a cat must be accommodated in order to understand that this is true (Phillips, 1969).

Research relating to social cognitions has attempted to demonstrate how situational stimuli are able to directly trigger cognitions, emotions, motivations and behaviours without personal choice or intentions by the individual. There are some basic assumptions throughout research on automatic processing that have directed previous research. First, it is assumed that automatic processes can run to completion without conscious regulation, once started. Second, automatic processes are developed through consistent and frequent pairing and organization of stimuli to responses. Third, automatic processing of information will reflect the constancies of one's life. Additionally, triggering situations will vary for different types of automatic processes. For some, the individual's conscious intention is required to commence the process, and for other automatic processing, the presence of the stimuli is all that is required. Repeated 
exposure to triggering stimuli will enable the schema to be more accessible, and will affect how future triggering will be interpreted (Todorov \& Bargh, 2002).

\section{Measurement of Deviant Sexual Interests}

Deviant sexual arousal may be measured more easily than deviant sexual interests because of its physical nature. For example, sexual arousal may be measured by monitoring changes in heart rate, or through the measurement of changes in penile circumference (plethysmography).

Measuring sexual interests is a more difficult task than measuring sexual arousal because of its psychological nature. Despite the difficulties in measuring deviant sexual interests, several researchers have attempted to do so through the examination of criminal histories, self-report measures, length of visual reaction times, plethysmography (themed) and implicit attitude tests (IAT). A brief overview of these methods will follow in order to understand and appreciate previous attempts made at measuring this difficult implicit concept, and the need for improved methods of measuring cognitions without having to rely on direct self-report measures.

First, through an examination of criminal history, or details of index offences, it is possible to gain some insight into the offenders' sexual preferences, such as preferred age of victims and the acts perceived as sexually gratifying used during the offence. A difficulty that may arise is that often criminal history records are incomplete or do not provide sufficient amounts of information that might inform researchers of the offender's interests (Stalans, 2004).

The Clarke Sex History Questionnaire (SHQ) (Langevin, Paitich, Handy, \& Langevin, 1990) is a self-report questionnaire that was developed specifically to meet the 
need of a clinically useful and sound psychometric instrument that documents the sexual history of sexual offenders. The SHQ is useful in identifying erotic preferences of participants, distinguishing between different types of offenders and is easily administered. In addition to exploring sexually deviant behaviours and outlets, the SHQ includes questions relating to desires and disgust in order to be testable with samples that have not actually performed sexually deviant behaviours, but to which the desires may be present. The questionnaire consists of 225 items (1990 version) that relate to the frequency and type of erotic outlet, including heterosexual and homosexual behaviours, cross-dressing, pedophilia, masturbation fantasies, voyeurism, obscene telephone calls, exhibitionism, frotteurism, and rape. Examples of outlets include dating, kissing, and contact with specific areas of the body such as breasts, anus and mouth (Paitich, Langevin, Freeman, Mann, \& Handy, 1977).

Certain sections of the Clarke Sex History Questionnaire have also been used in research. For example, Curnoe and Langevin (2002) examined the presence of deviant sexual fantasies in a sample of sex offenders and non sex offenders using a subsection (Fantasy scale) of the SHQ and found that homosexual pedophiles were deviant fantasizers $(56.5 \%)$ more often than other groups of sex offenders.

Self-report measures are not limited to paper and pencil questionnaires. Some researchers have looked at self-report ratings of sexual arousal following presentation of sexually arousing scenarios (Laws \& Osborn, 1983), rank ordering of slides according to the individual's personal preference (Quinsey, Steinman, Bergersen, \& Holmes, 1975), or rating the attractiveness of slides (Wormith, 1986). 
A common criticism of self-report measures is that they may not offer any additional information past what plethysmography (PPG) and criminal record information can. When dealing with forensic samples, another difficulty with self-report measures is that sexual offenders are not always willing to accept responsibility for their offending behaviours, and may deny their offences (Abel, Jordan, Hand, Holland, \& Phipps, 2001).

Traditionally, sexual interests have been measured using penile plethysmography (phallometric testing), which measures changes in the circumference of the penis following the presentation of sexual stimuli. Phallometric assessments can aid in the determination of sexual preference and identification of likely victims for sexual offender populations. Although plethysmography is a valid measure of sexual interests of sexual offenders, there are several limitations involved in the use of this measure. First, there are ethical concerns surrounding the depiction of nude photos of adults, and especially of children. There have been arguments that these pictures victimize those depicted. Some might also argue that plethysmography is invasive. Additionally, researchers are at risk of being detained when crossing American borders with these materials, whether it is used for research purposes or not (Abel, Huffman, Warberg and Holland, 1998; Murphy \& Barbaree, 1998).

In addition to ethical considerations, the administration of phallometric tests and the training of clinicians and researchers that is required to properly administer phallometric testing is time consuming and costly. Furthermore, some individuals may not produce erectile responses that are interpretable (Abel et al., 1998; Murphy \& Barbaree, 1998). Fakeability can also be an issue with PPG measures. If the offender is 
aware that phallometric testing will take place, it is possible for the offender to masturbate prior to testing, and limit their reactions to the depictions presented. Additionally, it is possible for individuals to force themselves to be aroused to the depictions of adult females, look away from the screen, or suppress erections when children are presented on the screen (Langevin, 2004).

Finally, the ability of plethysmography to yield accurate results with offenders that engage in exhibitionism, voyeurism, sexual aggression or rape has been questioned, due to difficulties in accurately depicting these types of scenes visually. Moreover, phallometric testing has a weak to moderate test-retest reliability (Langevin, 2004).

Despite these limitations, plethysmography has been used to monitor sexual interests and arousal with sexual offenders, and can be used in addition to self-report and counsellor judgments (multi-method approach). Plethysmography can provide the advantage of not having to rely solely on the offender's word, or counsellor judgments (Priest \& Smith, 2001).

Previous research has also indicated that there are correlations between the amount of time spent looking at a depiction of a person and the sexual interest of the subjects in that person. Therefore, as an alternative to PPG, Abel, Huffman, Warberg and Holland (1998) have used length of visual reaction time (VRT) to gain insight into the sexual interests of offenders. In visual reaction time research, individuals are presented with pictures (in this case, depictions of different ages and genders of people) and are asked to rate the level of sexual arousal (for example 'highly sexually arousing') reached from each depiction. The amount of time that is spent looking at the picture prior to the rating being made is recorded. Comparisons are made between the 'looking time' and 
the rating made by the subject to test whether they are consistent with each other (Abel et al., 1998). Zamansky (1956) found that homosexual males spent more time looking at depictions of males, while heterosexual males spent longer looking at pictures of females. Additionally, Wright and Adams (1994) found that heterosexual females and homosexual males looked at depictions of males for a significantly longer period of time than homosexual females and heterosexual males.

Abel and colleagues (1998) have also compared the reliability and validity measures of PPG to VRT measures, and found that both methods have the ability to accurately measure the sexual interests of sexual offenders. The reliability of the plethysmography ranged between .66 and .97 , and the visual reaction time method was between .84 and .90 . The percentage of correctly classified offenders using plethysmography ranged between $71.2 \%$ and $88.5 \%$, and between $76.7 \%$ and $91.2 \%$ in the visual reaction time experiments. Results from both plethysmography and visual reaction times were compared with self-report measures of sexual interest, and both consistently found that self-reported interests of the admitted sexual offenders were accurately reflected using these methods.

Due to the type of depictions that are used, similar ethical concerns that arise with PPG measures arise when using VRT measures. For example, Abel and colleagues (1994) did not use nude photos, nor did they use photos that might imply sadism, aggression, or coercion due to ethical considerations. A difficulty when omitting these depictions is that if the sexual offender being tested performed these types of behaviours in their offending pattern, it could not be identified through this type of test (Abel, Lawry, Karlstrom, Osborn, \& Gillespie, 1994). 
Furthermore, Lalumière and Quinsey (1994) have reported difficulty classifying sex offenders that deny their crimes, compared to those that admit to their crimes.

Therefore, rationalization and minimization of offending behaviours may also impede accurate findings. Letourneau (2002) reported moderate to high rates of internal consistency for both PPG and VRT methods used (see Table 3). The PPG and VRT methods used in this study did not, however, significantly correlate with the female adolescent stimulus category or the female child stimulus category. The author attributes these results to possible faking, suppression of arousal or the lack of identification of age ranges (Letourneau, 2002).

Table 3

Cronbach's Coefficient Alpha Correlations for VRT Slide Categories (Letourneau, 2002). Stimulus set

\begin{tabular}{lllll}
\hline & \multicolumn{2}{c}{ Caucasian } & \multicolumn{2}{c}{ African American } \\
Category & $\begin{array}{l}\text { Untrimmed } \\
\text { latencies }\end{array}$ & $\begin{array}{l}\text { Trimmed } \\
\text { latencies }\end{array}$ & $\begin{array}{l}\text { Untrimmed } \\
\text { latencies }\end{array}$ & $\begin{array}{l}\text { Trimmed } \\
\text { latencies }\end{array}$ \\
Female (2-4) & .87 & $.91(\mathrm{n}=17)$ & .72 & $.86(\mathrm{n}=23)$ \\
Female (8-10) & .86 & $.77(\mathrm{n}=17)$ & .87 & $.78(\mathrm{n}=18)$ \\
Female (14-17) & .85 & $.87(\mathrm{n}=11)$ & .83 & $.56(\mathrm{n}=11)$ \\
Female (22 and over) & .80 & $.92(\mathrm{n}=14)$ & .79 & $.77(\mathrm{n}=13)$ \\
Female (sadism) & .84 & $.91(\mathrm{n}=21)$ & N/A & N/A \\
Male (2-4) & .60 & $.82(\mathrm{n}=38)$ & .72 & $.93(\mathrm{n}=15)$ \\
Male (8-10) & .75 & N/A (n=5) & .87 & $.93(\mathrm{n}=17)$ \\
Male (14-17) & .90 & $.86(\mathrm{n}=21)$ & .87 & $.93(\mathrm{n}=14)$ \\
Male (22 and over) & .90 & $.85(\mathrm{n}=17)$ & .87 & $.90(\mathrm{n}=11)$ \\
Male (sadism) & .76 & $.87(\mathrm{n}=24)$ & N/A & N/A \\
\hline
\end{tabular}

In order to address limitations that each individual measure presents, Abel and colleagues developed the Abel Assessment for sexual interest (AASI). The AASI was developed to function as a tool to measure sexual interests of child molesters, and to aid in the development of treatment plans once sexual interests had been identified. The 
AASI consists of a visual reaction time task, a self-report sexual history questionnaire and a self-report arousal rating of depictions of males and females from several different age groups. The depictions used in the AASI currently do not use nude stimuli, but rather use depictions of clothed individuals (i.e., dressed in bathing suits). Comparisons are made between the self-report sexual history questionnaires, self-report arousal ratings and the latency periods between ratings for consistency across all measures. Abel and colleagues (2001) demonstrated the AASI's ability to accurately classify child molesters versus non-child molesters (criterion validity), and it's ability to resist false accounts of offending behaviours (Abel et al., 2001).

Rather than relying on physical arousal and self-report measures, more recent attempts to measure sexual interests with sex offender populations have focused on measuring the strength of automatic associations that individuals hold toward specific stimuli presented using the Implicit Association Test (IAT). The task requires participants to press a button when they are presented with a specific stimulus category and then press a separate button when presented with a second stimulus category. For example, participants may be required to press the left button when presented with male faces, and the right button when presented with female faces. This experiment would then be followed by a second experiment with opposite requirements. Therefore, when presented with male names the participant would be required to press the right button, and then the left button when presented with female names. The second experiment then becomes slightly more difficult due to the previous association formed when male faces were left, and female faces were right. 
Egloff and Schmukle (2002) used IAT measures to assess the strength of association between anxiety and the self. Previous research with the IAT has yielded internal consistency results of approximately 0.80 and test-retest reliabilities ranging from 0.32 to 0.69 . Egloff and Schmukle (2002) found similar results with an internal consistency finding of approximately 0.80 , and a test-retest value of 0.57 . The authors found that the IAT-anxiety test is able to measure the strength of association that individuals attribute between anxiety and themselves as anxious individuals.

Gray, MacCulloch, Smith, and Snowden (2002) used an Implicit Attitudes Test with a sample of pedophiles to measure their implicit beliefs regarding sexual interests and sexually arousing stimuli, an association that pedophiles are often highly motivated to conceal. There are two conditions used in this study. First, in the congruent condition, sex words and adult words are paired with the same response key, and the second response key to non-sex and child-themed words would be the same. In the incongruent condition, one response key would be used for sex-themed and child-themed words, and the second key would be assigned to the non-sex and adult-themed words. Ordinarily, with normals, the congruent condition is fairly simple, and longer latencies are observed in the incongruent condition because associations between sex and children are not previously established with normals.

Gray and colleagues (2002) found that the sixty non-sex offenders in the sample had significantly shorter latency periods for the congruent condition, and the pedophiles performed significantly more quickly in the incongruent condition, or displayed a negative IAT effect. The negative IAT effect suggests that pedophiles associate sex with children more than they do an adult/sex association. In other words, child molesters have 
a stronger implicit cognitive association between sex and children. The authors emphasize the importance of being able to access implicit beliefs about sexual offending, and doing so without using invasive methods.

\section{The Emotional Stroop Task}

The Stroop Colour-Naming Task has a long history in the field of psychology. Developed by J. Ridley Stroop in 1935, the Stroop task has been widely used across many different samples in psychological research. Researchers have explored the utility of the Stroop in identifying interference in automatic information-processing. The original Colour-Naming Stroop Task consisted of word lists of colours printed in five different colours of ink: red, blue, green, brown and purple. Each colour word is printed in a different colour than the actual word. For example, the word "red" might be written in blue ink. The participant would then be required to name the colour that the word is printed in, rather than read the word "red". The aim of the researcher would be to measure the amount of interference in automatic processing that occurs from being inhibited to automatically read the word. The latency period between the presentation of the word and the naming of the colour is the measure of interference in automatic processing.

Stroop (1935) conducted two separate experiments examining interference caused by simultaneous stimulus presentation (word stimuli and colour stimuli). First he compared latency periods of reading colour words written in different coloured ink to reading colour words written in black ink. For example, Stroop measured how long it took to read the word "red" written in blue ink, to the word "red" written in black ink. The results were not significantly different in that it took only 2.3 seconds longer to read 
100 colour words in different coloured ink, than to read that same list of words written in black ink.

In the second experiment, Stroop changed the task by having participants name the colour of ink that the word was written in, as opposed to simply reading the word. Therefore, if the word "red" were presented in blue ink, participants were required to call the answer "blue". This challenge resulted in much longer latency periods, where the mean response time for 100 words presented increased to 110.3 seconds from 63.3 seconds. Therefore, participants habitually found it easier to simply read the word, but when the task was to interrupt their habitual response to read, latency periods increased.

The Stroop task measures the different levels of association between target words and the individual's cognitions. Habitually, individuals will want to read the word that is presented. The latency period that is experienced is a measure of the level of association between the individual and the word stimuli. For example, if the word "cat" is presented, the amount of time that it takes the participant to name the colour that the word is presented in, reflects the level of emotional attachment, or association that the individual has with the word stimuli. Concomitantly, when the word "sex" is presented, participants having a high level of emotional attachment or cognitive associations relating to sex will take longer to name the colour that the word "sex" is presented in (Stroop, 1935).

Since Stroop (1935) developed the Stroop Colour-Naming Task, many modified versions have surfaced. The underlying concept of measuring habitual interference in information processing has remained the same, but by changing the word lists from words that are used everyday life such as "couch" or "pants", to words that may hold close meaning to participants such as "anxious" or "depressed" with clinical samples, the 
task has allowed for researchers to examine other routes of automatic informationprocessing. Just as tying ones shoes may be considered automatic, so may thinking depressing thoughts may be automatic to a clinically depressed individual. Therefore, by replacing colour words with clinical words such as "failure" researchers are able to determine whether that type of thinking has become habitual or automatic to the participant. If the latency periods are longer for words such as "failure", than they are for words such as "winner", then the participant may hold automatic information-processing functions that relate to depression. Knowing about such information processing bias can be of considerable interest to clinicians of the cognitive-behavioural tradition.

These modified versions of the Stroop task have been used in a wide area of psychological research such as with phobias, anxiety disorders, depression, addictions, violent offences and sexual offences. An overview of the history of use of the Stroop task in psychological research will demonstrate its wide range of applicability, and its ability to distinguish between automatic information processing of samples with particular dysfunctions and samples without the dysfunction in question.

\section{Stroop and alcohol.}

Kramer and Goldman (2003) examined differences in Stroop latencies between mild and heavy drinkers in a primed experiment. The alcohol expectancy target words included words such as relaxed and dizzy for light drinkers, and brave and wild for the heavy drinkers. Prime words were of two types: alcoholic beverages and non-alcoholic beverages. The authors found that longer latency periods were evident for mild drinkers with expectancy words related to being relaxed and tired, whereas heavy drinkers displayed longer latencies when expectancy words related to being horny, brave or wild. 
Therefore, heavy drinkers associate drinking more with being wild and crazy, in comparison to mild drinkers who associated drinking more with a feeling of being sedated and relaxed (Kramer \& Goldman, 2003).

Stroop and smoking opportunity.

Wertz and Sayette (2001) examined the relation between nicotine addiction and sensitivity to drug-related cues in smokers. Specifically, Wertz and Sayette (2001) used an unblocked format and found that smokers who were told they could smoke during the experiment displayed longer latencies than smokers who were told that they could not smoke. The smokers told that they "might" be able to smoke displayed no significant results. Therefore, when given the potential opportunity to smoke, interference effects resulted.

Several other Stroop studies have observed the effects of attentional bias with smokers (Gross, Jarvik, \& Rosenblatt, 1993; Waters \& Feyerabend, 2000; Wertz \& Sayette, 2001). Gross, Jarvik and Rosenblatt (1993) found that when presented with smoking-related stimuli in a blocked format (related words are presented together) abstinent smokers displayed longer latencies than non-abstinent smokers. Waters and Feyerabend (2000) examined the difference in latencies between abstinent and nonabstinent smokers using both blocked and unblocked (words are presented randomly from all word categories in a mixed order) formats. Waters and Feyerabend (2000) were able to replicate the results found by Gross et al. (1993) in the blocked format, but their results were not similar when using an unblocked format. 


\section{Stroop and phobia research.}

Holle, Neely, and Heimberg (1997) used the Stroop to examine possible cognitive structures that are anxiety-specific in samples of individuals with social phobias. The authors were interested in determining whether individuals with social phobias have an automatic-processing structure that is hypersensitive to threat-related material. For example, if such cognitive structures existed with social phobics, then latency periods for words pertaining to threat-related materials would be longer than latency periods of a word not related to threat. The idea here is that if the individual is not sensitive to the word presented, or if the word presented has no sensitive meaning to them (for example, the word "neutral"), then the path taken to process that word and name the colour will be "shorter" than it would be to process a word such as "anxious" where a specific information-processing route exists. The more meaning a word has to a certain individual, the longer it will take for the individual to process the word and name the colour, because there are more cognitive structures relating to that word available to pass through before the colour can be named. Hence, longer latency periods would result.

Holle et al. (1997) used a modified version of the Stroop with three word lists (social threat words, semantically related neutral words, and unrelated neutral words) on a sample of DSM-III-R diagnosed social phobics. Holle and colleagues (1997) compared latency reaction times to social threat words of social phobics in a blocked and random format. Significant differences in latencies between three different word types (social threat words, related neutral words and unrelated neutral words) were found when using a blocked format, but were not found when using random presentation of word stimuli. The authors conclude that many previous research findings may have been 
overestimating Stroop effects, and that priming effects may be the cause of such differences. Limitations did exist in this study that may also offer an explanation for these findings. First, there was no control group used; therefore, for the random presentation of stimuli, significant differences may have surfaced between the social phobics and a normal control group. Second, only four words per category were used with several trials, which means that the stimulus words were presented often. Longer latency periods for threat-related words were recorded although a lack of a control group for this study was a definite limitation.

Nevertheless, Holle et al.'s (1997) general finding that anxious individuals display longer latencies with social threat words than with neutral words have been replicated in additional studies (Arnold \& Cheek, 1986; Hope, Rapee, Heimberg, \& Dombeck, 1990; Mattia, Heimberg, \& Hope, 1993; McNeil et al., 1995). Arnold and Cheek (1986) found that shy undergraduate students displayed longer latency effects to social phobia cues than less shy undergraduates. McNeil et al. (1995) examined Stroop interference effects between three different groups: speech phobia participants, generalized social phobia participants and generalized social phobia and avoidant personality participants. Results displayed interference effects for the individuals with speech phobias to be less than both groups with general social phobias, which indicated that this group's phobia did not overlap into more general phobias relating to social anxieties. The results also indicate that individuals with general social phobias have implicit associations with social cues and anxiety.

Watts, McKenna, Sharrock and Trezise (1986) used the Stroop task to test whether spider-phobics displayed strong emotional salience to spider-related words. The 
authors found that spider-phobics were significantly slower to respond to spider-related words with the modified Stroop task than non-phobics.

Koven, Heller, Banich, \& Miller (2003) reported a threat Stroop effect when comparing Stroop latency periods between those classified as high versus low anxiety based on scores from the Anxiety Sensitivity Index (ASI). Those that reported higher levels of anxiety took longer to respond to the modified Stroop than those who seldom self-reported feelings of anxiety. The authors attribute the interference effect to the inability of highly anxiety sensitive individuals to self-distract themselves when anxiousrelated materials are presented.

A study conducted by Mogg, Bradley, Williams and Mathews (1993) found Stroop effects with participants that exhibit high levels of anxiety and negative words stimuli. Participants suffering from depression were also part of this study, but did not exhibit similar effects when presented with negative stimuli. Additionally, contentspecific Stroop effects were not evident in this study. It was hypothesized that highanxiety participants would display longer latencies for anxiety-specific stimuli, and that depressed participants would show larger Stroop effects for negative affect stimuli. Instead, the results indicated that high-anxious participants were slower to colour-name for all negative stimuli, which implied that high-anxious individuals contain more implicit associations with negative cues in general than depressed individuals.

\section{Stroop and depression.}

Hill and Knowles (1991) found no Stroop effects when comparing reaction times of depressed and non-depressed participants to threatening words. The lack of differences in latency periods may have something to do with their methodologies used. 
First, cards were used that held 100 words per card, and participants were to continue naming colours until the card was complete. Each card contained one type of stimulus set (blocked), for example one card would contain all neutral words, or all positive words. This method may interfere with the participant's ability to name the colour as they are looking at a card full of colours when attempting to concentrate on one word stimulus at a time, and thoughts about previous words presented may have been interfering due to massed presentation (Foa, Feske, Murdock, Kozak, \& McCarthy, 1991).

Second, a stopwatch was used to time latency periods and timing began with the first word on the card, and ended with the last word on the card. Times were recorded in half seconds, using a stopwatch. This could be considered an added limitation of the study since more accurate methods of measurement exist and milliseconds may be recorded. Overall the depressed participants were slower at colour-naming, and had more accurate methods been used, perhaps significant results would have been evident.

Finally, the study actually displayed that words relating to threats to self-esteem do not differentiate between depressed and non-depressed individuals. The authors used threat-related stimuli (the words reflected what the authors saw as being threats to selfesteem) as opposed to depressed-related stimuli. The choice of words could have been more specific to general depression symptoms or themes (Hill \& Knowles, 1991).

Klieger and Cordner (1990) examined the strength of association of negative affect words and depressed subjects. The results displayed that mild and moderate levels of depression in participants revealed larger interference effects with this task as compared to non-depressed participants. No significant differences were present between 
the two groups (mild vs. moderate) of depressed participants. The Beck Depression Inventory (BDI) was used to determine what level of depression participants reached. Perhaps the inclusion of highly depressed participants would have yielded more conclusive results.

\section{Stroop and rape victims.}

Foa et al., (1991) compared latencies to rape-related words between rape victims with PTSD, rape victims without PTSD and non-rape victim controls. The rape victims with PTSD displayed significantly longer latencies than the other two groups. The rape victims without PTSD exhibited longer latencies than the control group, but these findings were not significant. The authors suggest that the PTSD group possess stronger schema, or stronger associations between the word stimuli and schema related to rape and danger than the other two groups and this is why they take longer to complete the colournaming task. An additional finding of this study is that the PTSD group's reaction time to the word "grape"was very similar to the response times from the rape-themed words.

\section{General Stroop findings.}

All of the studies conducted with the Stroop hold something in common: longer latency periods were found for each dysfunction identified in the study. Whatever the focus of the modified Stroop task, it has consistently been found that Stroop effects are greater when the words included relate specifically to the problem in examination (Logan \& Goetsch, 1993). Since it is assumed that deviant sexual interests have a cognitive component, and the Stroop task has consistently shown its ability to measure salient cognitive information, it seems reasonable to assume that the same methods can be used 
to measure cognitive processing mechanisms of sexual information with sex offender populations.

\section{Replication of a Study}

The present study aimed to replicate and expand on previous research conducted by Smith and Waterman (2004) that examined Stroop interference effects of sexual and aggressive word stimuli for violent and sexual offender populations. Smith and Waterman used a sample of 30 offenders: 10 sexual offenders, 10 violent offenders and 10 non-violent offenders. The emotional Stroop task was administered to all participants and comprised of neutral words, aggression-related words, positive and negative affect words, color words and sexual words (See Appendix A), which were presented randomly across all word categories. It was hypothesized that sexual offenders would display longer latency reaction times to sexually themed words, and violent offenders would take longer to name the colour of aggression-themed words. The basis of these hypotheses was that the sexually themed words would be more salient to sexual offenders and the aggressive words would be more salient to violent offenders.

Factorial ANOVA was used to analyze the data, and the results exhibited a significant interaction effect between group and word type. The hypotheses were confirmed in this experiment and the sexual offenders displayed significant interference for the sexually themed words. Additionally, violent offenders had significantly longer latencies toward aggression themed words compared to the sexual offenders. In addition to these results, the sexual offenders that were more aggressive in their offending behaviours (rapists) had longer latency reaction times to aggression-themed words, than the sexual offenders that were less overtly violent. For the sexual material alone, sexual 
offenders did not respond differently between sexual offender groups (e.g., rapists versus child molesters). Smith and Waterman (2004) then concluded that the way in which information is perceived by different types of offenders will activate different cognitive associations, and these associations are reflected in the Stroop latencies.

Smith and Waterman (2004) recognized the limitations of their study. First, the mood questionnaires were administered prior to the completion of the Stroop task and this might have made sexual materials more accessible while the Stroop task was being carried out, and may have had an effect on the results. Second, the sample size was quite small in this study, and replications should attempt to increase the sample size.

\section{The Present Study}

The present study aimed to replicate and expand on the experiment conducted by Smith and Waterman (2004). The methodologies used in their research were also used in this study, and a second experiment was conducted to explore the limitations that Smith and Waterman (2004) addressed in their study. The same hypotheses were assumed: it was expected that sexual offenders would display longer latencies to sexually themed words over the violent offenders, and that violent offenders would have stronger Stroop interference effects towards aggression themed words. Additionally, it was expected that the non-violent, non-sexual offenders would yield Stroop effects most similar to the pilot study sample of non-offenders.

The second experiment of this study included new word lists that were created to examine whether different types of sexual offenders (i.e., rapists and child molesters) displayed discriminating latencies to words that were specific to their crimes. Therefore, it was expected that child molesters would have more Stroop interference effects to child- 
themed (e.g., playground, molest, child) words than rapists would, and that rapists would have longer latencies for more aggressive sexual words (e.g., dominate, screw, slut). It was expected that we would be able to discriminate between different types of sexual offenders on account of the salience of the words used as stimuli to their offending behaviours, and more readily accessible schemas.

The present study considered the limitations listed by Smith and Waterman (2004) by increasing the sample size and administering limited amounts of questionnaires relating to sexual behaviours and sexual experiences prior to the completion of the Stroop task. The rape attitudes scale, and attitudes towards child molestation scale were administered following the Stroop tasks. An additional limitation that was addressed in this study was the choice of sexual word stimuli used by Smith and Waterman.

\section{Method}

\section{Participants}

All participants were Caucasian, and native English speakers with a minimum grade 10 educational level in order to minimize cultural, vocabulary or literacy biases related to word content. All participants were volunteers and were required to complete questionnaires regarding their offence history and index offence (Appendix B and C), general self-report sexual history (Appendix D), vocabulary abilities (Appendix E), attitudes towards rape (Appendix F) and child molestation (Appendix F), and informed consent forms (Appendix G). The sample of offenders was drawn from five Kingston Ontario Institutions: Millhaven Institution, Kingston Penitentiary, Bath Institution, Warkworth Institution and Pittsburgh Institution. Participants were informed that they may withdraw from the study at any point. 
The sample used in this study consisted of different types of sexual offenders. The sexual offenders were classified based on type of victim: extra familial child molesters (3), incest offenders (12), and rapists (15). A sample of violent non-sexual offenders (15), non-violent, non-sexual offenders (15) and a community sample (15) were used as comparison groups. Three categories of offenders were used in this experiment in order to be able to compare the samples regarding saliency of word content. The community sample was selected from a sample of acquaintances and coworkers of the researcher.

\section{Inclusion/exclusion criteria.}

Because the hypotheses concerned the sexual interests and cognitions of different types of offenders, inclusion and exclusion criteria were needed to form the offender groups.

First, participants were categorized as violent offenders if they were currently imprisoned for a crime involving a confrontation with their victims (e.g., robbery, assault, or domestic homicide). Participants from this category were eliminated from the study if they had previously been convicted of a sexual offence, or had self-reported having been involved in a sexual offence.

Participants were classified as rapists if they had offended against a sexually mature individual (e.g., aged 14 or older), and used force to obtain sexual access. The rapists may or may not have had additional violent offences, but were excluded from this study if they admitted to, or had previously been convicted of a sexual offence against a child. 
The child molesters that were included in this study had offended against a physically immature individual aged 12 and under, or used coercion through a position of trust up to the age of 18 (e.g., a 14 year old with a teacher). These offenders were excluded from this category if they had committed a sexual offence against an adult, or used more force than necessary to commit the offence. For example, participants who used brutality to gain sexual access to a child were excluded from this study.

Finally, the non-sexual, non-violent offenders included those that had been convicted of drug or property crimes and have not been convicted for a violent offence during the last ten years.

These criteria were intended to minimize overlapping of offender types, and to ensure that the results reflected the accessible schema of specific types of offenders. For example, if a rapist had offended against both adults and children, their schema relating to sexual offending would be less distinctive as an offender type and this study was aiming to determine whether specific types of offenders may be differentiated between using word lists specific to their offending behaviours.

\section{Apparatus/Materials}

Word stimuli were presented using a modified version of the Emotional Stroop colour-naming task using SuperLab Pro software (Cedrus Corporation) on a 12"x 9" screen of a Dell notebook 2.8 Pentium 4 computer. The colour-identification response latency for each trial was detected and recorded by an SV-1 Smart Voice Key (Cedrus Corporation).

Information concerning the offenders' age, marital status, marital history, relationship history, victim gender, relationship of victim to the offender, age of sexually 
abused victims, primary language and ethnicity was collected through self-report questionnaires and file review (Appendices B, C and D).

The Clarke Vocabulary Test (Appendix E) was administered to ensure that reading level of the offender was sufficient for the completion of the Stroop task. The Clarke Vocabulary Scale is a self-administered vocabulary test and has produced a correlation of .913 with the WAIS Vocabulary Test (Paitich, 1977).

A ten-item version of Bumby's Rape Attitude Scale (Appendix F) was completed to examine self-report cognitive distortions related to rape. The scale has demonstrated strong internal consistency and reliability. The respondents base their decisions on a five point Likert scale ranging from "strongly disagree" to "strongly agree" and high total scores indicate stronger cognitive distortions relating to rape (Bumby, 1996). The scale takes approximately five minutes to complete.

The Hanson Sex Attitudes Questionnaire (SAQ) (Appendix F) was used to measure the self-reported attitudes towards child molestation of the offenders in the sample. The SAQ is originally made up of 47 items, but a shortened version of the SAQ (29 items) was administered in this study to shorten the time needed with each participant. The items in this scale yield high internal consistencies and differentiated between incest offenders and physically abusive men (Hanson, Gizzarelli, \& Scott, 1994).

Finally, because we were interested in whether different levels of risk would affect the latency responses to the Stroop task, the Static-99 (Hanson \& Thornton, 2000) was coded for each sexual offender. The Static-99 is an actuarial risk tool designed to predict sexual and violent recidivism among adult male sexual offenders. It contains 10 
items: Age less than 25, Never lived with a lover for two years, Any prior convictions for non-sexual violence, Any current convictions for non-sexual violence, 4 or more prior sentencing dates, Prior sexual offences, Non-contact sexual offences, Any male victims, Any unrelated victims and Any stranger victims (see Harris, Phenix, Hanson \& Thornton, 2003 for detailed coding rules). All items are accorded one point, with the exception of Prior sexual offenders, where up to 3 points can be given. Previous studies have found high levels of rater reliability $(\mathrm{r} \approx .90$; Harris et al., 2003, p. 79), and moderate accuracy in predicting sexual recidivism risk (average $\mathrm{d}$ of .63 , based on 5,103 offenders from 21 studies; Hanson \& Morton-Bourgon, 2004). Risk categories are based on the following raw scores: 0-1 "Low", 2-3 "Moderate-Low", 4-5 "Moderate-High" and 6-12 "High".

Data management and confidentiality.

Access to offender psychology files was requested to complete the Static-99 items and file review. All information gathered was kept anonymous, and offender information was managed using a numbering system. No identifying variables were collected in this study (i.e., name of offender).

\section{Design and Procedures}

Participants began by completing consent forms that informed them of the information that would be collected and what procedures would be completed throughout the length of the study. Participants then completed two brief questionnaires relating to their offence history and demographic information such as age, gender and marital status. Following a short break, participants were instructed on the procedures of the Stroop task and were given twenty practice trials of colour words. Following the practice trials, Experiment 1 began. 


\section{Experiment 1.}

Experiment 1 comprised a replication of Smith and Waterman's (2004) study on processing bias with the emotional Stroop task and offenders. The word lists used (created by Smith and Waterman) were identical to those used in their study (see Appendix A) and were presented in the same manner. An " $x$ " appeared at the centre of the screen for $500 \mathrm{~ms}$ followed by a word. There were six types of words presented: neutral (25), aggression-themed (25), positive emotion words (25), negative emotion words (25), sexually-themed words (25), and colour words (25). Participants were asked to name the colour in which the word was presented and to ignore the meaning of the word. Words were presented in four different colours (red, green, blue or yellow) and with the colour-word list no word was presented in the colour that is named. Presentation of words followed a random format where each word had the same likelihood of appearing on the screen, but each word was not presented on more than one occasion.

The researcher was a 26-year-old female university student. In order to minimize experimenter effects, the experimenter stood behind the offenders while completing both Stroop tasks, so not to distract the participants. Once the first Stroop experiment was complete, participants were required to fill out the Clarke Vocabulary Scale, followed by the second Stroop experiment.

\section{Experiment 2.}

Experiment 2 consisted of a newly developed set of sexually-themed word lists (Appendix A) created by the authors: a child molester word category and a rape-themed word list. It was the intention of this experiment to differentiate between different types of sexual offenders and to determine whether different types of sexual offenders hold 
different schema relating to their behaviours and whether these schema will be evident through the administration of the Stroop task.

In addition to the two offender-specific word lists that were added in this experiment, an intimacy-themed word list was added. It was hypothesized that due to a lack of intimacy skills with sexual offenders, the participants that were categorized as such would have shorter latency reactions to these types of words due to their deficiencies in intimacy skills, and lack of association with intimate themes.

Word lists were created to represent sexual activities that would be of interest to rapists and child molesters. These word lists along with a word list of intimacy words were presented in alphabetical order to five judges (university students known to the researcher). Words for which three or more judges agreed were considered to represent each category. Of 30 child molester words, 15 were classified as child molester words (e.g., "molest", "helpless") and 10 words were rated as intimacy/sex words (e.g., "flirt", "kiss") (five were rejected). Twenty-one of the 28 rape words were identified as such (e.g., "bitch", "force"), four words being classified as intimacy/sex (e.g., "ass", "naked") (three were rejected). Four or more of the five judges agreed on all the intimacy words, of which 25 were retained. The word lists were designed to be presented in a fixed order so that the association between adjacent words provided the desired connotation (e.g., "submit" followed by "naked" for rapists, and "suck" followed by "pee pee" for child molesters). Neutral words were selected from a word frequencies research book (Dahl, 1979) and were matched for length of word and word frequency.

The main reason for the addition of three new word categories was that the sexual words presented in Smith and Waterman's (2004) study were a mixture of both rape and 
child molesting words in one category. It was the intention of this study to expand on previous research and to explore whether different types of sexual offenders could be differentiated between if presented with word lists relating to their specific type of sexual offending behaviours. Once all Stroop tasks were completed participants then filled out the questionnaires relating to attitudes towards sexual offending (Bumby's rape scale and Hanson's sexual attitudes questionnaire), and were then debriefed.

\section{Hypotheses}

1. Interference for type of word will be linked to the offenders' own offence history.

2. More interference will be demonstrated by high-risk offenders based on the results from the Static-99 file review.

3. Depending on the nature of the deviant sexual interests and attitudes held by each offender, interference effects will vary. For example, high scores on the "Sexy Kids" section of Hanson's SAQ will correlate with child molester interference scores on the Stroop. The score on Bumby's Rape Attitudes Questionnaire will be highest among the rapist sample. Finally, high scores on the Sexual Entitlement scale will correlate highly with Stroop effects of sexual words with sex offenders.

4. Both explicit and implicit attitudes (Stroop) will contribute to group differentiation.

\section{Analyses}

Responses were identified as outliers using Box and whisker plots. Extreme responses would be considered outliers when the reaction time was less than $360 \mathrm{~ms}$ or greater than $2100 \mathrm{~ms}$. 
Bias scores were calculated in the same manner as Smith and Waterman (2004) by subtracting the mean reaction times to neutral words from each of the mean reaction times to stimulus word conditions (sexual, aggression, positive, negative and colour). In the second experiment the stimulus word conditions were child molester themed, rapist words and intimacy words.

For Experiment 1, the bias scores (colour, positive emotion, negative emotion, aggression and sexual) were entered into separate one-way ANOVA's and compared between participant types (child molester, rapist, violent offender, non-violent non-sexual offender and community sample). For Experiment 2 the bias scores (child molester, rapist and intimacy) were entered into one-way ANOVA's and compared between participant types (child molester, rapist, violent offender and non-violent non-sexual offender and community sample). Additionally, correlations between participants' selfreported attitudes towards sex, Statis-99 scores and Stroop interference effects were explored.

To measure the average difference between the sexual offenders and the nonsexual offenders an effect size indicator, $d$, was used and is defined as follows: $d=\left(M_{1}-M_{2}\right) / S_{\mathrm{w}}$, where $\mathrm{M}_{1}$ is the mean of the sexually deviant group (rapists and child molesters), $\mathrm{M}_{2}$ is the mean of the non-sexual offenders (violent offenders and non-violent non-sexual offenders), and $S_{\mathrm{w}}$ is the pooled within standard deviation (Hasselblad \& Hedges, 1995). It should be noted here that because we were not provided with all of the standard deviations of the sexual bias scores from Smith and Waterman's sample, the pooled standard deviation for their sample was estimated (averaged from the two standard deviations of the sexual bias scores provided in their study). 
According to Cohen (1988), $d$ values of .20 are considered "small", .50

"medium", and .80 "large". Therefore, in this case, if a $d$ value of .20 were obtained there would be little variation between the two groups. The variance of the $d$ statistic was calculated using the following: $\operatorname{Var}\left(d_{i}\right)=\left[\frac{N_{1}+N_{2}}{N_{1} N_{2}}+\frac{d_{i}{ }^{2}}{2\left(N_{1}+N_{2}\right)}\right]$, and was used to calculate the $95 \%$ C.I. $=d \pm\left(\operatorname{Var}\left[d_{i}\right]\right)^{1 / 2}$. When the $95 \%$ confidence interval for $d$ does not contain zero, it can be considered statistically significant at $\mathrm{p}<.05$. When the confidence intervals for two predictors do not overlap, they can be considered different from each other $(\mathrm{p}<.05)$.

In order to examine the direct replication for variation and generalizability of effects across studies, Hedges and Olkin's (1985) $Q$ statistic was used: $Q=\sum_{i=1}^{k} w_{i}\left(d_{i}-d .\right)^{2}$. The $Q$ statistic is distributed as a $\chi^{2}$ with $k-1$ degrees of freedom $(k$ is the number of studies). A significant $Q$ statistic indicates that there is more variability across studies than would be expected by chance. The averaged $d$ value was calculated, $d$., by weighing each $d_{i}$ by the inverse of its variance: $d .=\left(\sum_{i=1}^{k} w_{i} d_{i}\right) /\left(\sum_{i=1}^{k} w_{i}\right)$, where $k$ is the number of findings, $w_{i}=1 / v_{i}$, and $v_{i}$ is the variance of the individual $d_{i}$ (fixed effect model).

The variance of the weighted mean was also calculated to complete the $95 \%$ confidence interval for the replication analysis: $\operatorname{Var}(d)=.1 /\left(\sum_{i=1}^{k} w_{i}\right) ; 95 \%$ C.I. $=d . \pm$ $(\operatorname{Var}[d .])^{1 / 2}$ 
Results

Eighty-six offenders were approached to take part in this study. The researcher rejected 12 participants, either because the participant was not appropriate for this study (i.e., their Clarke scores were too low, non-violent participants had a prior violent offence or sexual offence), or because they were unable to properly complete the Stroop task. Additionally, 14 participants refused participation in this experiment. The final analysis of data then was completed on a sample of 60 offenders ( 15 rapists, 15 child molesters, 15 violent offenders and 15 non-violent non-sexual offenders). Additionally, pilot data for 15 community participants was added to the analysis for comparison purposes between offender and non-offender samples.

Table 4

Demographics, Mean Responses to Questionnaires, and Rejected Responses (with standard deviations)

\begin{tabular}{llllll}
\hline & Rapists & $\begin{array}{l}\text { Child } \\
\text { Molesters }\end{array}$ & Violent & Non-Violent & Community \\
\hline Age & $37.6(11.17)$ & $46.6(12.00)$ & $34.0(9.91)$ & $34.2(9.53)$ & $32.33(10.29)$ \\
Clarke Score & $5.60(1.68)$ & $6.33(1.29)$ & $5.93(1.16)$ & $6.20(1.01)$ & \\
$\begin{array}{l}\text { Static-99 Score } \\
\text { Rejected }\end{array}$ & $4.14(2.28)$ & $1.21(1.72)$ & & & \\
$\begin{array}{l}\text { Responses } \\
\text { Wrong Colour }\end{array}$ & $7.27(3.92)$ & $9.00(3.02)$ & $6.73(4.56)$ & $8.60(5.94)$ & \\
$\begin{array}{l}\text { Responses } \\
\text { Skipped Responses }\end{array}$ & $1.00(2.36)$ & $3.13(2.36)$ & $1.93(2.02)$ & $1.60(1.18)$ & $1.40(1.20)$ \\
$\begin{array}{l}\text { Response Too } \\
\text { Slow }\end{array}$ & $2.07(2.12)$ & $3.80(3.26)$ & $2.73(2.71)$ & $2.47(3.20)$ & $1.97(1.83)$ \\
\hline
\end{tabular}

There was a significant effect of age, $\mathrm{F}(4,70)=4.361, \mathrm{p}<.005$, with the child molesters being significantly older than the community and non-violent non-sexual offenders. The participants in this study were, on average, seven years older than Smith and Waterman's (2004) sample. The average age of sexual offenders in the present study 
was 42.1 and the sexual offenders from Smith and Waterman's sample were on average 35.6 years old. Additionally, there was a significant difference between the rapists and the child molesters regarding their mean static scores, $\mathrm{F}(1,26)=14.716, \mathrm{p}<.005$, where the rapists displayed significantly higher static-99 scores.

There were no significant differences between the groups concerning number of response times removed from the analyses, although the sexual offenders seemed to make more "wrong colour" responses. Responses where noise from the institutions or setting caused the program to skip would qualify as "skipped" responses. When the response times were more than $2,100 \mathrm{~ms}$ they were removed from the analyses and were counted as "responses too slow". Consequently, the total number of responses rejected includes responses that were too slow, the skipped responses, and responses where the wrong colour was named. The mean number of responses that were rejected included both Experiment 1 and Experiment 2 word stimuli.

To test the first hypothesis (interference for type of word would be linked to the offenders' own offence history) bias scores were calculated by subtracting the mean reaction time to neutral words from the mean reaction times of the stimuli word categories (positive, negative, colour, aggression, sexual, child molestation, rape, and intimacy). From these calculations, eight bias scores were produced for each participant. It is important to note that a positive bias score would indicate that the participants were slower to name the colour of the word for the stimuli word categories, and that Stroop interference was experienced by the participants. Table 5 lists the mean reaction times (with standard deviations), and mean bias scores per group for Experiment 1 Stroop 
trials, and Table 6 displays the mean reaction times (with standard deviations), and mean

bias scores per group for Experiment 2 trials.

Table 5

Participant Mean Response Times in Milliseconds, ms, and Bias Scores (With Standard Deviations in Parentheses) for Experiment 1 Stroop Task

\begin{tabular}{|c|c|c|c|}
\hline Word class & Group & $\begin{array}{c}\text { Mean Response time, } \\
\text { ms }\end{array}$ & Bias score, ms \\
\hline \multirow[t]{5}{*}{ Neutral } & Child molesters & $871.405(111.266)$ & \\
\hline & Rapists & $881.063(100.391)$ & \\
\hline & Violent offenders & $839.407(86.164)$ & \\
\hline & Nonviolent offenders & $826.644(115.598)$ & \\
\hline & Community sample & $750.888(112.290)$ & \\
\hline \multirow[t]{5}{*}{ Positive emotion } & Child molesters & $890.665(107.722)$ & $19.260(52.16)$ \\
\hline & Rapists & $922.738(115.622)$ & $41.675(56.44)$ \\
\hline & Violent Offender & $867.476(116.532)$ & $28.070(55.63)$ \\
\hline & Nonviolent offenders & $853.301(137.930)$ & $26.657(54.14)$ \\
\hline & Community sample & $753.900(96.870)$ & $3.007(28.84)$ \\
\hline \multirow[t]{5}{*}{ Negative emotion } & Child molesters & $910.319(116.133)$ & $38.914(44.61)$ \\
\hline & Rapists & $915.227(129.614)$ & $34.164(65.20)$ \\
\hline & Violent offenders & $876.835(97.373)$ & $37.429(36.61)$ \\
\hline & Nonviolent offenders & $862.824(124.748)$ & $36.180(41.07)$ \\
\hline & Community sample & $756.486(85.782)$ & $5.600(41.40)$ \\
\hline \multirow[t]{5}{*}{ Color } & Child molesters & $951.901(123.496)$ & $80.495(69.14)$ \\
\hline & Rapists & $930.996(117.958)$ & $49.934(49.14)$ \\
\hline & Violent offenders & 886.077 (103.784) & $46.671(51.30)$ \\
\hline & Nonviolent offenders & $849.347(104.545)$ & $22.702(48.27)$ \\
\hline & Community sample & $767.659(88.964)$ & $16.772(45.96)$ \\
\hline \multirow[t]{5}{*}{ Aggression } & Child molesters & $882.804(113.581)$ & $11.399(56.61)$ \\
\hline & Rapists & $887.497(123.119)$ & $6.435(68.89)$ \\
\hline & Violent offenders & $856.047(112.465)$ & $16.641(48.31)$ \\
\hline & Nonviolent offenders & $814.021(128.885)$ & $-12.624(59.72)$ \\
\hline & Community sample & $734.036(78.082)$ & $-16.852(47.36)$ \\
\hline \multirow[t]{5}{*}{ Sexual } & Child molesters & $960.150(146.639)$ & $88.744(79.78)$ \\
\hline & Rapists & $1013.286(182.428)$ & $132.224(111.21)$ \\
\hline & Violent offenders & $930.723(136.638)$ & $91.316(69.00)$ \\
\hline & Nonviolent offenders & $904.629(165.923)$ & $77.985(76.84)$ \\
\hline & Community sample & $777.723(101.954)$ & $26.835(70.51)$ \\
\hline
\end{tabular}

Bias scores were entered into a one-way ANOVA with offender type as the between-subjects variable. A significant difference was found between groups for the 
sexual word bias scores, $F(4,70)=3.112, \mathrm{p}<.05$. Bonferroni corrected post-hoc tests showed that rapists were significantly slower to colour-name sexually themed words compared to the community sample $(\mathrm{p}<.05)$, and were also slower, but not significantly slower than the child molesters, violent offenders, and non-violent non-sexual offenders. Additionally, the child molesters significantly differed from the community and nonviolent non-sexual offender groups, $F(4,70)=3.373, p<.05$, when naming the colour words, and were slower that the rapists and violent offenders, but this difference was nonsignificant.

Table 6

Participant Mean Response Times in Milliseconds, ms, and Bias Scores (With Standard Deviations in Parentheses) for the Experiment 2 Stroop Task

\begin{tabular}{llll}
\hline Word Class & Group & $\begin{array}{l}\text { Mean Response } \\
\text { Time, ms }\end{array}$ & Bias Score, ms \\
\hline Neutral & Child molesters & $848.428(112.195)$ & \\
& Rapists & $888.602(111.543)$ & \\
& Violent offenders & $875.315(139.093)$ & \\
& Nonviolent offenders & $805.097(112.353)$ & \\
& Community Sample & $726.586(99.638)$ & \\
\hline Child molestation & Child molesters & $927.826(142.402)$ & $79.078(55.73)$ \\
& Rapists & $992.680(185.211)$ & $104.078(113.27)$ \\
& Violent offenders & $935.723(151.998)$ & $60.408(83.24)$ \\
& Nonviolent offenders & $878.257(170.844)$ & $73.160(93.90)$ \\
& Community Sample & $778.143(116.550)$ & $51.556(37.21)$ \\
\hline Rape & Child molesters & $962.762(147.707)$ & $114.335(74.77)$ \\
& Rapists & $982.844(169.773)$ & $94.242(124.94)$ \\
& Violent offenders & $1002.522(176.05)$ & $127.207(105.03)$ \\
& Nonviolent offenders & $904.066(200.769)$ & $98.968(128.25)$ \\
& Community sample & $816.806(139.804)$ & $90.219(66.70)$ \\
\hline Intimacy & Child molesters & $865.402(131.869)$ & $16.973(68.28)$ \\
& Rapists & $902.004(122.415)$ & $13.402(59.17)$ \\
& Violent offenders & $851.131(134.167)$ & $-24.184(59.40)$ \\
& Nonviolent offenders & $832.512(147.940)$ & $27.415(92.38)$ \\
& Community sample & $721.276(115.681)$ & $-5.310(32.08)$ \\
\hline
\end{tabular}


In addition to the significant differences in bias scores, it is important to note that there were also significant differences between the means of the neutral words for the rapists and child molesters, $F(4,70)=3.560, p<.05$, whom took significantly longer than the community sample to colour-name.

For Experiment 2, no significant differences were found when the bias scores were entered into one-way ANOVAs.

In addition to the analyses conducted on word categories between offender types, it was of interest to the researchers to determine whether any individual words were more salient to certain offender types. Several words were exclusively salient to rapists, child molesters and violent offenders (based on individual reaction times to each word). For example, the rapists took significantly longer to colour-name several words, when compared to the community sample: "rape", "control", "dominance", "force", "prostitute”, "touch”, “boy", “caress”, “care”, “accept”, “secret”, “partner”, “play”, "dependent" and "affection". The child molesters were significantly slower to colourname the words "molest", "pee pee", and "like", compared to the community sample. Finally the violent offenders took significantly longer to respond to the word "tits", when compared to the community sample. Both violent offenders and rapists shared significant differences in latencies for the following words: "victim", “anal", "restrain", "naked", "incest", "friend", "cuddle", "hug" and "intimate" when compared to the community.

There were no significant differences found between groups for the mean scores (see Table 7) on Bumby's Rape Attitudes Scale, or on the Sexy Kids Scale from Hanson's Sex Attitudes Questionnaire (SAQ). A significant relationship was found between the sex bias score and the responses to the Sexual Entitlement Scale of the SAQ 
$(r=-.253 ; \mathrm{p}<.05)$, but this relationship was in the opposite direction than what was

expected. This correlation shows that when sex bias scores become greater, Sexual

Entitlement scores become lower.

Table 7

Mean Responses to Self-Report Sexual Questionnaires, With Standard Deviations

Rapists Child Violent Non-Violent Community

Molesters

$\begin{array}{llllll}\text { Bumby } & 12.93(4.73) & 10.73(2.76) & 10.33(1.76) & 13.0(3.16) & 10.8(2.18)\end{array}$

$\begin{array}{llllll}\text { Sexy Kids Scale } & 13.33(2.06) & 12.0(2.88) & 12.93(1.67) & 13.67(3.94) & 12.47(.74)\end{array}$

$\begin{array}{llllll}\text { Sexual Entitlement } & 14.4(3.56) & 14.0(4.66) & 14.8(5.09) & 15.47(5.13) & 15.67(3.20)\end{array}$

The results of the analyses conducted thus far have not demonstrated that explicit and implicit attitudes have contributed to group differentiation, as the results have not displayed significant differences between the offender types, nor have they displayed significant differences between offenders' results on the self-report measures and their mean bias scores for Stroop interference.

To further the investigation regarding group differentiation between offender types, the effect size indicator, $d$, was used to measure the average difference between the sexual offenders and the non-sexual offenders (excluding community and undergrad samples for both studies).

The $d$ statistic obtained for the present study using the mean sexual bias scores was $d=.3068(95 \%$ confidence interval of -.202 to .816$)$, and indicates that there was little variation between the sexual bias scores for the sexual offenders and the non-sexual offenders. Smith and Waterman's (2004) sample displayed a moderate relationship between the sexual and non-sexual offenders $(d=.53$, confidence interval of -.241 to 1.3$)$ for their sexual bias scores (i.e., greater variation between the two groups). 
For the direct replication analysis, the averaged $d$ value, $d$., for the two studies was .3746 (confidence interval of -.050 to .80 ), with no significant variability across the two studies $(Q=.224, \mathrm{~ns})$. Therefore, the offenders from the present study were similar to those from Smith and Waterman's sample.

\section{Discussion}

The results of the present study are similar to those found by Smith and Waterman (2004), in that they demonstrate similar patterns of mean reaction times and bias scores. Although the mean latencies displayed by the participants in the present study are approximately $150 \mathrm{~ms}$ slower across all word categories than those produced by Smith and Waterman's participants, offender groups demonstrated longer latencies in similar word categories. For example, the violent offenders displayed more interference for the aggression-themed words than the other offenders, as well as the negative words. Additionally, the sexual offenders (as one group) displayed longer latencies to the sexually themed words than the other offenders. Smith and Waterman found significant differences between the sexual offenders and their undergraduate sample for the sexual bias scores, and the present study yielded significant differences between the community sample and sexual offenders.

The present study yielded results that were weaker than those found by Smith and Waterman (2004) but the general direction of the Stroop findings were the same. Analysis between sexual offenders and other offenders displayed little variability between the two types of offenders in the present study, and only moderate variation was exhibited between these two groups in Smith and Waterman's study. Additionally, the results of this study showed that there was also little variation between the two study 
samples (the present study and Smith and Waterman's); therefore, the groups were exhibiting similar reactions to the Stroop task.

The next directive should be to develop Stroop tasks that will be able to yield significant differences between offender types. If further research were to be conducted using the Stroop task to differentiate between offender samples, then perhaps it would be useful to conduct preliminary research that would examine the types of thoughts and motives that are experienced by these types of offenders while committing sexual crimes. For example, if we were to ask a rapist what words come to mind when reflecting on his motivation to rape, and we were to include these words in a Stroop experiment, it may be more likely to yield significant differences between offender types.

It is not clear why the mean latencies were approximately $150 \mathrm{~ms}$ slower for the present study when compared to Smith and Waterman's sample, but this could be due to the software that was used, or perhaps the differences in mean age between the two samples.

Although similar patterns were present, there were clear differences between the two samples in mean latencies to neutral word stimuli. In the current study, significant differences between the sexual offenders and the community sample were present, yet these differences were not evident in Smith and Waterman's sample. In fact, the sexual offenders in Smith and Waterman's sample did not differ much from the undergraduate sample for the mean latencies of neutral words. This is important to note, as the bias scores depend on the mean reaction times for the neutral words to produce a Stroop effect. The sexual offenders in the present study were in fact slower to colour-name across many of the word categories. 
Significant differences were not evident in the analysis of Experiment 2, but the mean bias scores for Experiment 2 were much higher than those produced in Experiment 1. Therefore, it seems safe to say that the word stimuli were salient to all participants. This does not mean that all of the participants exhibit deviant sexual attitudes, but that perhaps the words used displayed a certain "shock value" and the initial reaction to these word stimuli may have masked any actual word preference for these stimuli by group.

Additionally, there are several potential explanations for the lack of significant differences in Experiment 2. First, the words that were developed for the purpose of differentiating between types of sexual offenders were not empirically derived. This may be problematic, as the words that were chosen may not actually reflect the motives, thoughts or feelings experienced by those committing sexual crimes. The findings here may indicate that more work needs to be done on the development of word stimuli. Again, perhaps future research in this area should take one step back and concentrate on the development of word stimuli that are mutually exclusive to differing offender populations.

The lack of significant results in Experiment 2 may also be due to the choice of child molester words, or the sample of child molesters used in this research. Recall that when judges rated the selected words as belonging to certain categories, only 15 of the 25 child molester words were rated as exclusively belonging to the child molester category. The remaining ten words were classified as intimacy/sex words. Therefore, it is possible that the child molester word stimuli were perceived as more sexual to the other offender types, and perhaps this narrative did not reflect the intentions and thoughts of the child molesters included in this analysis. Additionally, the child molesters that were included 
in this experiment were mostly incest offenders (12 out of 15 ), and displayed very low Static-99 scores, demonstrating a low risk to reoffend. Therefore, it is possible, that the word stimuli used in the child molester category did not reflect the motives and thoughts of incest offenders, but may have been more salient to extrafamilial child molesters. Since there were only three extrafamilial child molesters who took part in this experiment, separate analyses for this group were not conducted.

The separate analysis that was conducted on the individual words showed us that certain words were more salient to different offenders. For example, the words "pee pee", "molest", and "like" were more salient to the child molesters. The rapists and violent offenders seemed to have particularly aggressive words and intimacy words more salient to them. Perhaps these words that were more salient to specific types of offenders should be used in future analysis to determine whether this finding is replicable, and whether they truly reflect the schema of these offenders.

Smith and Waterman (2004) noted several limitations of their study. For one, their sample size was quite small, where they had 10 sexual offenders in total (5 violent sexual offenders and 5 non-violent sexual offenders), 10 violent offenders, 10 non-violent non-sexual offenders and 10 undergraduates. This study attempted to address this limitation by increasing the sample size from 43 to a sample size of 75 (using 30 sexual offenders instead of 10).

Smith and Waterman (2004) also noted that some of the questionnaires completed prior to the administration of the Stroop task may have affected the results and worked as primes to the offenders when completing the Stroop task. This study attempted to address this concern by conducting most of the sexual self-report questionnaires 
following the completion of the Stroop task experiments. Although this limitation was addressed, due to the format of the study, participants were required to answer general questions related to their sexual history prior to the Stroop task, which may have affected the results as well.

The results of the self-report sexual attitudes questionnaires did not reflect the anticipated results. It was anticipated that the community sample would display the lowest scores on each measure, and that depending on the type of sexual offence one was convicted of their scores on the sexual measures would vary. For example, it was expected that the rapists would score the highest on Bumby's Rape Attitudes Questionnaire. Instead, the non-violent non-sexual offenders scored highest. Additionally, it should be mentioned that the correlations between the Stroop bias effects and both scales on Hanson's SAQ were in the wrong direction. As the bias scores increased (more Stroop interference was experienced), the scores on these scales decreased. These results are not unheard of in forensic settings. Arkowitz and Vess (2003) found that the sexual offenders in their study yielded similar results to nonsex offenders, and the sexual offenders could not be distinguished between each other on the RAPE and MOLEST scales. The authors suggest that because the results of the instruments may have significant consequences for the offenders, the results may be manipulated in a self-serving manner.

A potential limitation of the present study is that the question of prior victimization of sexual or physical abuse was not addressed. In disregarding this question completely, it is possible that the non-sexual offenders exhibited salience to deviant sexual stimuli because they had been victims of sexual offences, and not because 
they held similar deviant sexual interests to sexual offenders. Therefore, it is possible that more clear differences between offender samples were avoided, because we did not screen for history of abuse. For example, had this research excluded victims of sexual abuse from the non-sexual offender categories of offenders, perhaps more significant findings would have been evident between the offender groups.

Previous research on sexual offenders has reported prevalence rates of $40 \%$ to $45 \%$ for physical abuse victimization and rates of sexual victimization of $30 \%$ to $50 \%$ (Hanson \& Harris, 2000; Hanson \& Slater, 1988). Dhawan and Marshall (1996) found that when offenders were surveyed about having been victims of contact sexual abuse, $50 \%$ of their incarcerated child molesters reported having been victims of these crimes while they were children, compared to $20 \%$ of incarcerated non-sexual offenders reporting this type of victimization. With these rates, it is possible that a number of the participants in this study were victims of child sexual abuse, and may have found the sexual word stimuli salient on account of this victimization. Unfortunately, because we did not include this type of questioning, we are unsure as to whether the sexual words are simply salient across offender types, or whether in addition to sexually deviant individuals, victims of sexual abuse display similar latencies to these types of word stimuli.

Additional concerns that should be addressed when using the Stroop task in forensic settings are the limitations produced by the setting itself. Since the Stroop task is voice activated, it is important that this type of research be conducted in a quiet and closed setting. There were several occasions throughout this study where noise produced from the institutional setting (i.e., doors or gates slamming, yelling and screaming from 
outside the room) caused the word stimuli to skip. The voice activation, although convenient for the purpose of recording reaction times, can be quite sensitive and institutional settings do not always provide the most quiet atmosphere to complete research in.

Future research should attempt to determine whether, following treatment, the Stroop task may be used to predict recidivism according to the strengths of association between treated sex offenders and sexual word stimuli. For example, if longer latencies to sexual word stimuli would imply that the sexual offender has strong cognitive associations with deviant sexual interests, then following treatment these associations should be weaker than they were prior to treatment. Therefore, pre-post latencies should indicate some measure of positive change and these change scores should be examined in future research. Additionally, research should examine whether the change scores have any relationship with recidivism. Although there were no significant differences in this study between offender samples, this may not indicate that difference scores will not be experienced pre/post treatment.

The results of this study, in addition to Smith and Waterman's results would suggest that cognitive processing does differ between sexual offenders and non offenders. Since the aim was to expand these findings to being able to differentiate between offending samples, further work still needs to be done. The results raise the question of how best to measure the attitudes and cognitive processes related to offending (the basis of cognitive-behavioural treatment). Some forms of cognitive measures hold promise, but none are sufficiently developed enough to be used in routine clinical practice. The Stroop task may hold promise in measuring the attitudes and cognitive processes related 
to offending, but research is still preliminary in this field, and may need to take a step back before being able to advance as a measurement tool in forensic settings. 


\section{References}

Abel, G.G., Huffman, J., Warberg, B., \& Holland, C.L. (1998). Visual reaction time and plethysmography as measures of sexual interest in child molesters. Sexual Abuse: A Journal of Research and Treatment, 10, 81-95.

Abel, G. G., Jordan, A., Hand, C. G., Holland, L. A., Phipps, A. (2001). Classification models of child molesters utilizing the Abel Assessment for sexual interest ${ }^{\mathrm{TM}}$. Child Abuse \& Neglect, 25, 703-718.

Abel, G.G., Lawry, S.S., Karlstrom, E.M., Osborn, C.A., \& Gillespie, C.F. (1994). Screening tests for pedophilia. Criminal Justice and Behavior, 21, 115-131.

Arkowitz, S., \& Vess, J. (2003). An Evaluation of the Bumby RAPE and MOLEST Scales as measures of cognitive distortions with civilly committed sexual offenders. Sexual Abuse: A Journal of Research and Treatment, 15, 237-249.

Arnold, A.P., \& Cheek, J.M. (1986). Shyness, self-preoccupation and the Stroop colour and word test. Personality and Individual Differences, 7, 571-573.

Beech, A.R., \& Ward, T. (2004). The integration of etiology and risk in sexual offenders: A theoretical framework. Aggression and Violent Behavior, 10, 31-63.

Bumby, K.M. (1996). Assessing the cognitive distortions of child molesters and rapists: Development and the validation of the molest and rape scales. Sexual Abuse: A Journal of Research and Treatment, 8, 37-54.

Bureau of Justice Statistics. (2003). Bureau of Justice Statistics: National Crime Victimization Survey. U.S. Department of Justice: Office of Justice Statistics. NCJ \#205455. 
Canadian Centre for Justice Statistics. (1999). Sex Offenders. Ottawa: Statistics Canada, Juristat Catalogue, no. 85-002-XPE.

Curnoe, S., \& Langevin, R. (2002). Personality and Deviant Sexual Fantasies: An examination of the MMPI's of sex offenders. Journal of Clinical Psychology, 58, 803-815.

Dahl, H. Word frequencies of spoken American English. Detroit, Mich.: Gale Research Co.

Dhawan, S., \& Marshall, W.L. (1996). Sexual abuse histories of sexual offenders. Sexual Abuse: A Journal of Research and Treatment, 8, 7-15.

Egloff, B., \& Schmukle, S.C. (2002). Predictive validity of an implicit association test for assessing anxiety. Journal of Personality and Social Psychology, 83, 1441-1455.

Finkelhor, D. (1982). Sexual abuse: A sociological perspective. Child Abuse \& Neglect, $6,95-102$.

Finkelhor, D. (1986). Abusers: Special topics. In A Sourcebook on Child Sexual Abuse. S. Araji, L. Baron, A. Browne, S.D. Peters, and G.E. Wyatt. Beverly Hills, CA: Sage Publications.

Finkelhor, D. (1993). Epidemiological factors in the clinical identification of child sexual abuse. Child Abuse \& Neglect, 17, 67-70.

Finkelhor, D., \& Lewis, I. (1988). An epidemiologic approach to the study of child molestation. Annals of the New York Academy of Social Sciences, 528, 64-67.

Finkelhor, D., Hotaling, G., Lewis, I.A., \& Smith, C. (1990). Sexual abuse in a national survey of adult men and women: Prevalence, characteristics and risk factors. Child Abuse \& Neglect, 14, 19-28. 
Foa, E.B., Feske, U., Murdock, T.B., Kozak, M.J., \& McCarthy, P.R. (1991). Processing of threat-related information in rape victims. Journal of Abnormal Psychology, $100,156-162$.

Gray, N.S., MacCulloch, M., Smith, J., \& Snowden, R.J. (2002, September). Abnormal associations between children and sex in paedophiles as measures by the covert association task (CAT). Presentation at the $7^{\text {th }}$ Biennial Conference of the International Association for the Treatment of Sexual Offenders, Vienna.

Gross, T.M., Jarvik, M.E., \& Rosenblatt, M.R. (1993). Nicotine abstinence produces content-specific Stroop interference. Psychopharmacology, 110, 333-336.

Hanson, R. K., \& Bussière, M. T. (1998). Predicting relapse: A meta-analysis of sexual offender recidivism studies. Journal of Consulting and Clinical Psychology, 66, $348-362$.

Hanson, R.K., Gizzarelli, R., \& Scott, H. (1994). The attitudes of incest offenders: Sexual entitlement and acceptance of sex with children. Criminal Justice and Behavior, $21,187-202$.

Hanson, R.K., \& Harris, A. J. R. (2000). Coding Manual for Stable-2000. Ottawa: Public Safety and Emergency Preparedness Canada.

Hanson, R.K., \& Harris, A.J.R. (2000). Where should we intervene? Dynamic predictors of sexual offense recidivism. Criminal Justice and Behavior, 27, 6-35.

Hanson, R.K., \& Morton-Bourgon, K. E. (2004). Predictors of Sexual Recidivism: An updated meta-analysis, (User Report 2004-02). Ottawa: Public Safety and Emergency Preparedness Canada. 
Hanson, R.K., \& Slater, S. (1988). Sexual victimization in the history of sexual abusers: A review. Annals of Sex Research, 1, 485-499.

Hanson, R.K., \& Thornton, D. (2000). Improving risk assessments for sex offenders: A comparison of three actuarial scales. Law and Human Behavior, 24, 119-136.

Harris, A., Phenix, A., Hanson, R.K., \& Thornton, D. (2003). Static-99 Coding Rules Revised - 2003. Ottawa: Public Safety and Emergency Preparedness Canada. Hasselblad, V., \& Hedges, L.V. (1995). Meta-analysis of screening and diagnostic tests. Psychological Bulletin, 117, 167-178.

Hill, A.B., \& Knowles, T.H. (1991). Depression and the 'Emotional' Stroop effect. Personality and Individual Differences, 12, 481-485.

Holle, C., Neely, J. H., \& Heimberg, R. G. (1997). The effects of blocked versus random presentation and semantic relatedness of stimulus words in response to a modified Stroop task among social phobics. Cognitive Therapy and Research, 6, 681-697. Hope, D.A., Rapee, R.M., Heimberg, R.G., \& Dombeck, M.J. (1990). Representation of the self in social phobia: Vulnerability to social threat. Cognitive Therapy and Research, 14, 477-485.

Hudson, S. M., Ward, T., \& McCormack, J. C. (1999). Offence pathways in sexual offenders. Journal of Interpersonal Violence, 14, 779-798.

Klieger, D.M., \& Cordner, M.D. (1990). The Stroop task as measure of construct accessibility in depression. Personality and Individual Differences, 11, 19-27.

Koven, N. S., Heller, W., Banich, M. T., \& Miller, G. A. (2003). Relationships of distinct affective dimensions to performance on an emotional Stroop task. Cognitive Therapy and Research, 27, 671-680. 
Kramer, D. A., \& Goldman, M. S. (2003). Using a modified Stroop task to implicitly discern the cognitive organization of alcohol expectancy. Journal of Abnormal Psychology, 112, 171-175.

Lalumière, M.L., \& Quinsey, V.L. (1994). The discriminability of rapists from non-sex offenders using phallometric measures: A meta-analysis. Criminal Justice and Behavior, 21, 150-175.

Langevin, R. (2004). Phallometric testing: Pros and cons. In R.K. Hanson, F. Pfäfflin, \& M. Lütz, Sexual Abuse in the Catholic Church: Scientific and Legal Perspectives (pp. 63-70). Vatican City: Libreria Editrice Vaticana.

Langevin, R., Paitich, D., Handy, L., \& Langevin, A. (1990). The Clarke Sex History Questionnaire. Oakville, Ontario: Juniper Press.

Laws, D.R., \& Osborn, C.A. (1983). How to build and operate a behavioral laboratory to evaluate and treat sexual deviance. In G.J. Greer \& I.R. Stuart (Eds.), The sexual aggressor: Current perspectives on treatment (pp. 293-335), New York: Van Nostrand Reinhold.

Letourneau, E.J. (2002). A comparison of objective measures of sexual arousal and interest: Visual reaction time and penile plethysmography. Sexual Abuse: A Journal of Research and Treatment, 14, 207-223.

Logan, A.C., \& Goetsch, V.L. (1993). Attention to external threat cues in anxiety states. Clinical Psychology Review, 13, 541-559.

Marshall, W.L. (1997a). The relationship between self-esteem and deviant sexual arousal in nonfamilial child molesters. Behaviour Modification, 21, 86-96. 
Marshall, W.L. (1997b). Pedophilia: Psychopathology and theory. In D.R. Laws and W. O’Donohue (Eds.), Sexual deviance: Theory, assessment and treatment (pp. 152174). New York: Guilford.

Marshall, W.L., \& Barbaree, H.E. (1990). An integrated theory of the etiology of sexual offending. In W.L. Marshall, D.R. Laws, \& H.E. Barbaree (Eds.), Handbook of Sexual Assault: Issues, Theories and Treatment of the Offender (pp. 257-275). New York, NY: Plenum Press.

Mattia, J.I., Heimberg, R.G., \& Hope, D.A. (1993). The revised Stroop color-naming task in social phobics. Behaviour Research and Therapy, 31, 305-313.

McNeil, D. W., Ries, B. J., Taylor, L. J., Boone, M. L., Carter, L.E., Turk, C. L., \& Lewin, M.R. (1995). Comparison of social phobia subtypes using Stroop tests. Journal of Anxiety Disorders, 9, 47-57.

Mogg, K., Bradley, B. P., Williams, R., \& Mathews, A. (1993). Subliminal processing of emotional information in anxiety and depression. Journal of Abnormal Psychology, 102, 304-311.

Murphy, W.D., \& Barbaree, H.E. (1998). Assessment of sexual offenders by measures of erectile response: Am examination of their psychometric properties. Washington, D.C.: National Institute of Mental Health, Antisocial and Violent Behavior Program Branch.

Osland, J.A., Fitch, M., \& Willis, E.E. (1996). Likelihood to rape in college males. Sex Roles, 35, 171-183.

Paitich, D. (1977). The Clarke Vocabulary Scale: A Multiple-Choice Estimate of WAIS Vocabulary Level. Clarke Institute of Psychiatry: Toronto, Ontario. 
Paitich, D., Langevin, R., Freeman, R., Mann, K., \& Handy, L. (1977). The Clarke SHQ: A clinical sex history questionnaire for males. Archives of Sexual Behavior, 6, 421-436.

Phillips, J.L. (1969). The Origins of Intellect: Piaget's Theory. San Francisco: W.H. Freeman.

Priest, R., \& Smith, A. (2001). Counselling adult sex offenders: Unique challenges and treatment paradigms. Journal of Counseling and Development, 71, 27-32.

Public Safety and Emergency Preparedness Canada. (2004, November). Corrections and Conditional Release Statistical Overview. Ottawa, Ontario, Canada.

Quinsey, V.L., \& Lalumière, M.L. (1995). Evolutionary perspectives on sexual offending. Sexual Abuse: A Journal of Research and Treatment, 7, 301-315.

Quinsey, V.L., Steinman, C.M. Bergersen, S.G., \& Holmes, T.F. (1975). Penile circumference, skin conductance, and ranking responses of child molesters and "normals" to sexual and nonsexual visual stimuli. Behavior Therapy, 6, 213-219.

Rind, B., Tromovitch, P., \& Bauserman, R. (1998). A meta-analytic examination of assumed properties of child sexual abuse using college samples. Psychological Bulletin, 124, 22-53.

Rubenzahl, S.A., \& Corcoran, K.J. (1998). The prevalence and characteristics of male perpetrators of acquaintance rape. Violence Against Women, 4, 713-725.

Shaffer, D.R. (1999). Developmental psychology: Childhood and adolescence ( $5^{\text {th }}$ ed.). Pacific Grove, CA: Brooks/Cole Publishing Company. 
Smith, P., \& Waterman, M. (2004). Processing bias for sexual material: The emotional Stroop and sexual offenders. Sexual Abuse: A Journal of Research and Treatment, $16,163-171$.

Stalans, L. J. (2004). Adult sex offenders on community supervision: A review of recent assessment strategies and treatment. Criminal Justice and Behavior, 31, 564-608.

Stroop, J.R. (1935). Studies of interference in serial verbal reactions. Journal of Experimental Psychology, 18, 643-662.

Todorov, A., \& Bargh, J. A. (2002). Automatic sources of aggression. Aggression and Violent Behavior, 7, 53-68.

Ward, T., Bickley, J., Webster, S.D., Fisher, D., Beech, A., \& Eldridge, H. (2004). The Self-Regulation Model of the Offence and Relapse Process: A Manual (vol. 1: assessment). Victoria, BC: Pacific Psychological Assessment Corporation.

Waters, A.J., \& Feyerabend, C. (2000). Determinants and effects of attentional bias in smokers. Psychology of Addictive Behaviors, 14, 111-120.

Watts, F.N., McKenna, F.P., Sharrock, R., \& Trezise, L. (1986). Colour naming and phobia-related words. British Journal of Psychology, 77, 97-108.

Wertz, J. A., \& Sayette, M. A. (2001). Effects of smoking opportunity on attentional bias in smokers. Psychology of Addictive Behaviors, 15, 268-271.

Wormith, J.S. (1986). Assessing deviant sexual arousal: Physiological and cognitive aspects. Advances in Behavior Research and Therapy, 9, 748-765.

Wright, L., \& Adams, H. (1994). Assessment of sexual preference using a choice reaction time task. Journal of Psychopathology and Behavioral Assessment, 16, 221-231. 
Zamansky, H.S. (1956). A technique for measuring homosexual tendencies. Journal of Personality, 24, 436-448. 
Stroop and Sex Offenders 69

Appendix A

Experiment Word Lists

Reproduced with permission of the copyright owner. Further reproduction prohibited without permission. 
Experiment 1: Emotional Stroop Words by Category (Smith \& Waterman, 2004)

\begin{tabular}{|c|c|c|c|c|c|}
\hline Neutral & Aggression & Positive & Negative & Sexual & Colour \\
\hline Door & Rage & Devotion & Abandoned & Rape & Purple \\
\hline Group & Anger & Affection & Abused & Lust & Grey \\
\hline Chair & Tear & Admire & Afraid & Slap & Flesh \\
\hline Telephone & Assault & Euphoric & Aggressive & Victim & Pink \\
\hline Dog & Kick & Fond & Agony & Slut & Orange \\
\hline Coat & Shout & Grateful & Angry & Whore & Scarlet \\
\hline Sofa & Punch & Tolerant & Arrogant & Fuck & Maroon \\
\hline Bag & Hate & Affectionate & $\mathrm{Bad}$ & Bitch & Crimson \\
\hline Diary & Argue & Amused & Bitchy & Child & White \\
\hline Newspaper & Temper & Love & Crazy & Woman & Black \\
\hline Eat & Fight & Joy & Cruelty & Force & Cyan \\
\hline Oven & Kill & Proud & Detest & Penetrate & Brown \\
\hline Floor & Punish & Fond & Envy & Control & Tin \\
\hline Shopping & Annoyed & Funny & Fear & Schoolgirl & Bronze \\
\hline Umbrella & Guilt & Glad & Frightened & Power & Mauve \\
\hline Windy & Scream & Comfortable & Fury & Dominance & Gold \\
\hline Radio & Crush & Beloved & Glum & Force & Silver \\
\hline Painting & Slash & Calm & Greed & Oral & Jade \\
\hline Milk & Smash & Peace & Hateful & Abuse & Topaz \\
\hline School & Cut & Daring & Spiteful & Incest & Emerald \\
\hline Ball & Wound & Cheerful & Suspicious & Molest & Purple \\
\hline Pencil & Injure & Warm & Rage & Man & Grey \\
\hline Cigarette & Threaten & Protective & Pain & Grope & Flesh \\
\hline Football & Knife & Hope & Lose & Prostitute & Pink \\
\hline Shoe & Wound & Lively & Misery & Anal & Orange \\
\hline
\end{tabular}


Experiment 2: Emotional Stroop Words by Category (Price, 2004)

\begin{tabular}{lllll}
\hline Neutral & \multicolumn{1}{c}{ Child } & Intimacy & Neutral & Rape \\
\hline Dishes & Molest & Friend & Post & Rape \\
Earth & Child & Share & Blink & Bitch \\
Bench & Touch & Respect & Popsicle & Humiliate \\
Dusty & Naked & Desire & Letter & Scream \\
Oven & Young & Cuddle & Leaf & Slut \\
Lid & Boy & Affection & Laundry & Violate \\
Umbrella & Buttocks & Darling & Tall & Cunt \\
Carrot & Caress & Hug & Crust & Plead \\
Library & Helpless & Partner & Present & Restrain \\
Cart & Girl & Trust & Say & Cum \\
Robot & Flirt & Love & Grain & Force \\
Doorway & Schoolyard & Support & Weight & Whore \\
Unit & Kiss & Intimate & Porch & Stalk \\
Biscuit & Innocent & Care & Arch & Fuck \\
Postcard & Fondle & Buddy & Wax & Ass \\
Juice & Naïve & Admire & Triangle & Dominate \\
Bulb & Lure & Bond & Lamp & Pain \\
Braces & Secret & Team & Toothpaste & Submit \\
Spinach & Suck & Like & Scene & Naked \\
Saturday & Pee Pee & Brother & Paper & Screw \\
Paint & Tempt & Accept & Spring & Control \\
Pie & Sex & Helpful & Load & Cock \\
Also & Play & Closeness & Window & Beg \\
Milkshake & Dependent & Warm & Note & Hurt \\
Rabbit & Incest & Sweetheart & Pets & Tits \\
\hline
\end{tabular}




\section{Appendix B}

Demographic and File Review Coding Sheet For Sexual Offenders 


\section{Sexual Offender Self-Report Demographic Sheet}

Instructions: Please fill in the following information about yourself.

Sex: (circle)

Male

Female

Age:

Date of Birth:

YY/MM/DD

Circle the highest grade you have completed:

$\begin{array}{llllllll}6 \text { or less } & 7 & 8 & 9 & 10 & 11 & 12 & 13\end{array}$

Some University/College

YES NO

University Degree

YES NO

Have you ever been married

(include common law)?

YES NO

Circle your current marital status: Single

Married

Common Law

Divorced

Separated

Widower

What was your longest relationship with an intimate partner/lover?

None $\quad 1-5$ yrs $\quad 6-15$ yrs $\quad 16-30$ yrs $\quad 30+$ yrs

Have you ever lived with an intimate partner/lover for a period of 2 years or more?

What is the longest period of time that you have lived with an intimate partner/lover?

What was your occupation prior to incarceration?

Have you ever been a participant in a sexual offender treatment program?

If so, how long ago were you a participant in this program? 
Sex Offender File Review Coding Sheet

Date:

Offender Number:

FPS \#:

Institution:

DOB:

Previous Criminal Record To Current Offence:

Yes No

Previous Offences (total):

$\begin{array}{lll}\text { Offence Date } & \text { Sentence }\end{array}$ 
STATIC 99 ITEMS (Sex Offenders):

\begin{tabular}{|c|c|c|c|c|}
\hline $\begin{array}{l}\text { Question } \\
\text { Number }\end{array}$ & Risk Factor & \multicolumn{2}{|l|}{ Codes } & Score \\
\hline 1 & Young & \multicolumn{2}{|c|}{$\begin{array}{l}\text { Aged } 25 \text { or older } \\
\text { Aged } 18-24.99 \\
\end{array}$} & $\begin{array}{l}0 \\
1\end{array}$ \\
\hline 2 & Ever lived with & \multicolumn{2}{|c|}{$\begin{array}{l}\text { Ever lived with lover for at } \\
\text { least two years? } \\
\text { Yes } \\
\text { No }\end{array}$} & $\begin{array}{l}0 \\
1\end{array}$ \\
\hline 3 & $\begin{array}{l}\text { Index non-sexual violence } \\
\text { - Any convictions }\end{array}$ & \multicolumn{2}{|c|}{$\begin{array}{l}\text { No } \\
\text { Yes }\end{array}$} & $\begin{array}{l}0 \\
1 \\
\end{array}$ \\
\hline 4 & $\begin{array}{l}\text { Prior non-sexual violence - } \\
\text { Any convictions }\end{array}$ & \multicolumn{2}{|l|}{$\begin{array}{l}\text { No } \\
\text { Yes }\end{array}$} & $\begin{array}{l}0 \\
1\end{array}$ \\
\hline 5 & Prior sex offences & $\begin{array}{l}\text { Charges } \\
\text { None } \\
1-2 \\
3-5 \\
6+ \\
\end{array}$ & $\begin{array}{l}\text { Convictions } \\
\text { None } \\
1 \\
2-3 \\
4+ \\
\end{array}$ & $\begin{array}{l}0 \\
1 \\
2 \\
3\end{array}$ \\
\hline 6 & $\begin{array}{l}\text { Prior sentencing dates } \\
\text { (excluding index) }\end{array}$ & \multicolumn{2}{|c|}{$\begin{array}{l}3 \text { or less } \\
4 \text { or more }\end{array}$} & $\begin{array}{l}0 \\
1\end{array}$ \\
\hline 7 & $\begin{array}{l}\text { Any convictions for non- } \\
\text { contact sex offences }\end{array}$ & \multicolumn{2}{|c|}{$\begin{array}{l}\text { No } \\
\text { Yes } \\
\end{array}$} & $\begin{array}{l}0 \\
1\end{array}$ \\
\hline 8 & Any unrelated victims & \multicolumn{2}{|l|}{$\begin{array}{l}\text { No } \\
\text { Yes }\end{array}$} & $\begin{array}{l}0 \\
1\end{array}$ \\
\hline 9 & Any stranger victims & \multicolumn{2}{|l|}{$\begin{array}{l}\text { No } \\
\text { Yes }\end{array}$} & $\begin{array}{l}0 \\
1 \\
\end{array}$ \\
\hline 10 & Any male victims & \multicolumn{2}{|c|}{$\begin{array}{l}\text { No } \\
\text { Yes }\end{array}$} & $\begin{array}{l}0 \\
1\end{array}$ \\
\hline & Total Score & \multicolumn{2}{|c|}{$\begin{array}{l}\text { Add up scores from } \\
\text { individual risk factors }\end{array}$} & \\
\hline
\end{tabular}

TRANSLATING STATIC 99 SCORES INTO RISK CATEGORIES

Score Label for Risk Category

0,1 Low

2,3 Moderate-Low

4,5 Moderate-High

6 plus High 
Code based on current and previous offences:

Victim \#:

Relationship to Offender: Girlfriend/Boyfriend Wife (Common Law or Married)

Related (fill in relation type:

Acquaintance

Stranger

No information

Age of Victim:

Sex of Victim: $\quad$ Male $\quad$ Female

Degree of Physical Injury: Non-contact

No physical injury

Any physical damage (bruises, cut), no weapon

Injury or weapon use

Life threatening victim injury (manslaughter, attempted murder)

Death

Death and mutilation

No information 


\section{Appendix C}

Demographic and File Review Coding Sheet for Non-Sexual Offenders 
Non-Sexual Offender Self-Report Demographic Sheet

Instructions: Please fill in the following information about yourself.

Sex: (circle) Male Female

Age:

Date of Birth:

YY/MM/DD

Circle the highest grade you have completed:

$\begin{array}{llllllll}6 \text { or less } & 7 & 8 & 9 & 10 & 11 & 12 & 13\end{array}$

Some University/College

YES NO

University Degree

YES

NO

Have you ever been married

(include common law)?

YES

NO

Circle your current marital status:

Single
Married
Common Law
Divorced
Separated
Widower

What is the longest period of time that you have lived with an intimate partner/lover?

Have you ever lived with an intimate partner/lover for a period of 2 years or more?

What was your occupation prior to incarceration? 
What are your current convictions for which you are currently serving time for?

Offence

Date

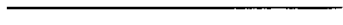

Do you have any previous convictions (If yes please list below):

Offence

Date

Sentence

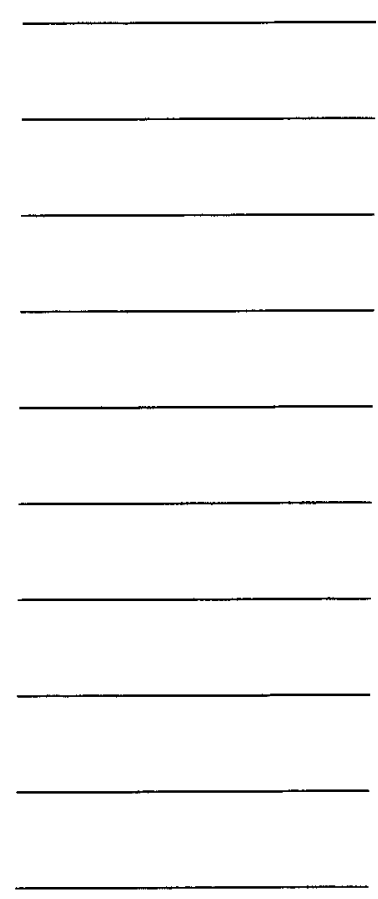

Have you ever been convicted of a sexual offence?
Sentence

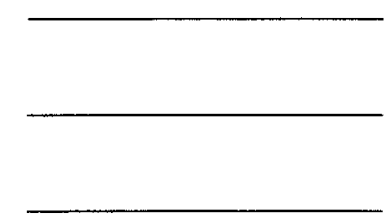


Non-Sex Offender File Review Coding Sheet

Date:

Offender Number:

FPS \#:

Institution:

DOB:

Previous Criminal Record To Current Offence:

Yes No

Previous Offences (total):

$\begin{array}{lll}\text { Offence Date } & \text { Sentence }\end{array}$ 
Code based on current and previous offences (Non-Sex Offenders):

Victim \#:

Relationship to Offender: Girlfriend/Boyfriend Wife (Common Law or Married)

Related (fill in relation type:

Acquaintance

Stranger

No information

Age of Victim:

Sex of Victim: $\quad$ Male $\quad$ Female

Degree of Physical Injury: Non contact

No physical injury

Any physical damage (bruises, cut), no weapon

Injury or weapon use

Life threatening victim injury (manslaughter, attempted murder)

Death

Death and mutilation

No information 
Stroop and Sex Offenders 82

Appendix D

General Self-Report Sex History Questionnaire 


\section{Self-Report Sexual History Questionnaire}

Instructions: The following are things that some people have done. Please circle the answer that best describes what you have done.

1. How many intimate partners/lovers have you had?

$\begin{array}{lllll}\text { None } & 1-5 & 6-15 & 15-30 & 30+\end{array}$

2. Of the sexual partners that you have had, how many were?

$\begin{array}{lllll}\text { All } & \text { Mostly } & \text { Both } & \text { Mostly } & \text { All } \\ \text { Male } & \text { Male } & \text { Male and } & \text { Female } & \text { Female }\end{array}$

Female

3(a). Have you ever had sexual intercourse with an adult female against her will?

Never Once $\quad$ Twice $\quad 3-5$ times 6 or more times

(b) How many different females?
None
1
2
3-5
6 or more

(c) Have you ever had sexual contact other than intercourse with an adult female against her will (e.g., touched her breasts, rubbed up against her)?

Never Once $\quad$ Twice $\quad 3-5$ times 6 or more times

(d) How many different females?

$\begin{array}{lllll}\text { None } & 1 & 2 & 3-5 & 6 \text { or more }\end{array}$

If you answered one or more to the above questions, please answer the next question. If not, skip to question 4.

(e) The woman/women involved in the above experiences was/were (check all that apply)

1. Stranger

2. Someone you just met

3. Someone you had known for a month or more

4. Girlfriend 

5. Wife/Spouse
6. Related to you (cousin)

4 (a) Have you ever had sexual intercourse with a female 13 years old or younger, when you were at lease five years older than her?
Never
Once
Twice
3-5 times
6 or more times

(b) How many different females?

$\begin{array}{lllll}\text { None } & 1 & 2 & 3-5 & 6 \text { or more }\end{array}$

(c) Have you ever had sexual contact (other than intercourse) with a female 13 years or younger, when you were at least five years older than her (e.g., touched her breasts, rubbed up against her)?

Never Once $\quad$ Twice $\quad 3-5$ times 6 or more times

(d) How many different females?

$\begin{array}{lllll}\text { None } & 1 & 2 & 3-5 & 6 \text { or more }\end{array}$

If you answered one or more to the above questions, please answer the next question if not skip to question 5 .

(e) The woman/women involved in the above experiences was/were (check all that apply).

1. Stranger

2. Someone you just met

3. Someone you had known for a month or more

4. Girlfriend

5. Wife/Spouse

6. Related to you (e.g., cousin)

5 (a) Have you ever had sexual contact with an adult male against his will?
Never
Once
Twice
3-5 times
6 or more times

(b) How many different males?
None
1
2
3-5
6 or more

(c) Have you ever had sexual contact with a male 13 years old or younger when you were at least five years older than him? 
(d) How many different males?

$\begin{array}{lllll}\text { None } & 1 & 2 & 3-5 & 6 \text { or more }\end{array}$

If you answered one or more to any of the above questions, please answer the next question.

(e) The men/males involved in the above experiences was/were (check all that apply):

1. Stranger

2. Someone you just met

3. Someone you had known for a month or more

4. Boyfriend

5. Wife/Spouse

6. Related to you (e.g., cousin) 
Stroop and Sex Offenders 86

Appendix E

Clarke Vocabulary Scale 


\section{Clarke Vocabulary Scale Instructions}

On the following page is a list of words. On the left, a word is underlined. Beside it are four choices. You are to circle the item that most closely matches the underlined word. Some of the words are common and some of the words are uncommon. You are not expected to know all of the words. It is o.k. to guess, but do not feel that you have to answer all the questions. 


\section{CLARKE VOCABULARY SCALE \\ (Daniel Paitich, PhD. D.}

INSTRUCTIONS: Please circle the response that has the most similar meaning to the underlined word.

\section{PLEASE CIRCLE THE APPROPRIATE RESPONSE}

\begin{tabular}{|c|c|c|c|c|c|}
\hline 1. & $\underline{\text { a book }}$ & A. is to read & B. is a ball & C. is blue & D. is to run \\
\hline 2. & $\underline{\text { a car }}$ & A. is a dance & B. is to drive & C. is black & D. is to eat \\
\hline 3. & $\underline{\text { a horse }}$ & $\begin{array}{l}\text { A. has four } \\
\text { legs }\end{array}$ & B. is small & $\begin{array}{l}\text { C. lives in a } \\
\text { house }\end{array}$ & D. flies \\
\hline 4. & $\underline{\text { a clock }}$ & $\begin{array}{l}\text { A. keeps you } \\
\text { dry }\end{array}$ & B. is deep & C. tells time & D. is for cats \\
\hline 5. & a hammer & $\begin{array}{l}\text { A. grows on a } \\
\text { tree }\end{array}$ & B. is a tool & $\begin{array}{l}\text { C. is for you } \\
\text { leg }\end{array}$ & D. has a shell \\
\hline 6. & a pillow & $\begin{array}{l}\text { A. is an } \\
\text { animal }\end{array}$ & B. is hard & $\begin{array}{l}\text { C. is to open } \\
\text { jars }\end{array}$ & D. is to sleep on \\
\hline 7. & a glove & $\begin{array}{l}\text { A. goes on } \\
\text { your hand }\end{array}$ & $\begin{array}{l}\text { B. goes on } \\
\text { your head }\end{array}$ & $\begin{array}{l}\text { C. is to work } \\
\text { with }\end{array}$ & D. is a tree \\
\hline 8. & a saw & $\begin{array}{l}\text { A. is to cut } \\
\text { with }\end{array}$ & B. is to sit on & $\begin{array}{l}\text { C. is to point } \\
\text { with }\end{array}$ & D. is a page \\
\hline 9. & $\underline{\text { Fur }}$ & A. is blue & $\begin{array}{l}\text { B. is animal } \\
\text { hair }\end{array}$ & C. is sweet & D. is on birds \\
\hline 10. & $\underline{\text { Jewel }}$ & A. round & B. sky & C. flower & D. diamond \\
\hline 11. & $\underline{\text { Connect }}$ & A. spill & B. part & C. join & D. feel \\
\hline 12. & Shovel & A. farm & B. spade & C. cry & D. ace \\
\hline 13. & Weapon & A. sword & B. correct & C. lip & D. pecan \\
\hline 14. & Nuisance & A. baby & B. help & C. worse & D. bother \\
\hline
\end{tabular}




\begin{tabular}{|c|c|c|c|c|c|}
\hline 15. & $\underline{\text { ridiculous }}$ & A. silly & B. ruined & C. poor & D. defenceless \\
\hline 16. & nimble & A. fat & B. active & C. brave & D. sick \\
\hline 17. & $\underline{\text { wager }}$ & A. court & B. dice & C. gamble & D. strike \\
\hline 18. & magnify & $\begin{array}{l}\text { A. make } \\
\text { smaller }\end{array}$ & B. distant & $\begin{array}{l}\text { C. make } \\
\text { bigger }\end{array}$ & D. handle \\
\hline 19. & $\underline{\text { fable }}$ & A. fur & B. watch & C. rhyme & D. story \\
\hline 20 . & facetious & A. hungry & B. witty & C. weighty & D. ugly \\
\hline 21. & blemish & A. flaw & B. abuse & C. vaunt & D. clean \\
\hline 22. & $\underline{\text { strife }}$ & A. try & B. verse & C. battle & D. wine \\
\hline 23. & $\underline{\text { seclude }}$ & A. ensure & B. dream & C. isolate & D. obtain \\
\hline 24. & recede & A. withdraw & B. deny & C. repeat & D. dine \\
\hline 25 . & profusion & A. glitter & B. plenty & C. noise & D. glory \\
\hline 26. & adversary & A. opponent & B. explosive & C. light & D. grammar \\
\hline 27. & effrontery & A. bombing & B. boldness & C. triviality & D. belief \\
\hline 28. & impending & A. valuable & B. prominent & C. imminent & D. obese \\
\hline 29. & abyss & A. confusion & B. suicide & C. monastery & D. chasm \\
\hline 30. & diverge & A. asset & B. vacation & C. distress & D. wander \\
\hline 31. & devoid & A. planet & B. vacuum & C. missing & D. insect \\
\hline
\end{tabular}




\begin{tabular}{|c|c|c|c|c|c|}
\hline 32. & arduous & A. laborious & B. shapeless & C. sterile & D. proud \\
\hline 33. & vigilant & A. watchful & B. careful & C. literal & D. winning \\
\hline 34. & relinquish & A. food & B. plague & C. distress & D. surrender \\
\hline 35. & catacomb & A. deep valley & $\begin{array}{l}\text { B. Japanese } \\
\text { garden }\end{array}$ & C. ruined city & $\begin{array}{l}\text { D. underground } \\
\text { cemetery }\end{array}$ \\
\hline 36. & indemnity & A. penalty & B. subsidy & C. amity & D. ordinance \\
\hline 37. & reprobation & A. approval & B. censure & C. slander & D. verification \\
\hline 38. & dilatory & A. slow & B. expanded & C. selfish & D. uncertain \\
\hline 39. & requite & A. admonish & B. love & C. repay & D. commend \\
\hline 40. & imprecation & A. inaccuracy & B. scruple & C. curse & D. rarity \\
\hline
\end{tabular}




\section{Clarke Scoring}

\section{Correct answers}

1. A

2. B

3. A

4. $\mathrm{C}$

5. B

6. D

7. A

8. A

9. B

10. D

11. C

12. B

13. A

14. D

15. A

16. B

17. A

18. C

19. D

20. B

21. A

22. $\mathrm{C}$

23. $\mathrm{C}$

24. A

25. B

26. A

27. B

28. C

29. D

30. D

31. C

32. A

33. A

34. D

35. D

36. A

37. B

38. A

39. C

40. $\mathrm{C}$

Total Score: 140 
Clarke Scoring: If the participant has less than 14 words correct (dull normal), the Questionnaire package will be invalid. The following is the interpretation key (from Paitich, 1977).

Very Superior----35-40 correct, $98 \mathrm{th}+$ percentile Superior--.-------30-34 correct, 91 to $97^{\text {th }}$ percentile Bright--..--------27-29 correct, 76 to $90^{\text {th }}$ percentile High average-----21-26 correct, 63 to $75^{\text {th }}$ percentile Average---.-----17-20 correct, 37 to $62^{\text {nd }}$ percentile Low Average----15-16 correct, 25 to $36^{\text {th }}$ percentile Dull Normal---.--11-14 correct, 9 to $24^{\text {th }}$ percentile Borderline--.----10 correct, 3 to $8^{\text {th }}$ percentile Retarded----------0-9 correct, 2 and below 
Appendix F

Bumby's Rape Myth Acceptance Scale and Hanson's Sex Attitude Questionnaire (SAQ) 
Bumby's Rape Myth Acceptance Scale (Short Version) and Hanson's Sex Attitude Questionnaire (Short Version)(SAQ)

\section{Instructions:}

This test measures how you think about women and sex. You will be presented with 30 statements which you are asked to rate on a scale ranging form strongly agree to strongly disagree. You are to circle which response you agree with. For example:

I think that the colour blue should only be worn on Mondays.

Strongly disagree

$$
1
$$

3
Strongly agree

4
5

Please complete the following:

1. Men who commit rape are probably responding to a lot of stress in their lives and raping helps to reduce that stress.

Strongly disagree

1

2

3

4

Strongly agree

5

2. Women who get raped probably deserve it.

Strongly disagree

1

2
3
Strongly agree

4

5

3. Women generally want sex no matter how they get it.

Strongly disagree

12
Strongly agree

3

4

5

4. Since prostitutes sell their bodies for sexual purposes anyway, it is not as bad if someone forces them into sex.

Strongly disagree

12
3

Strongly agree

3

4

5. If a woman does not resist strongly to sexual advances, she is probably willing to have sex.

Strongly disagree

12
3
Strongly agree

4

5 
6. Women often falsely accuse men of rape.

Strongly disagree

1
2

3

4

Strongly agree

7. A lot of women who get raped had "bad reputations" in the first place.

\section{Strongly disagree}

1
2

3
Strongly agree

4

8. If women did not sleep around so much, they would be less likely to get raped.

Strongly disagree

1
2

3

4

Strongly agree

9. If a woman gets drunk at a party, it is really her fault if someone takes advantage of her sexually.

Strongly disagree

1
2
Strongly agree

4

5

10. Some children are mature enough to enjoy sex with adults.

Strongly disagree

1
2

3
Strongly agree

4

5

11. A person should have sex whenever is needed.

Strongly disagree

1
2
Strongly agree

4

12. An eight year old child can enjoy a good sex joke.

Strongly disagree

1
2
3
Strongly agree

4
5 
13. Women should oblige men's sexual needs.

Strongly disagree

1
2

3

14. Some children like to sexually tease me.

Strongly disagree

1

3

4

Strongly agree

5

15. Everyone is entitled to sex.

\section{Strongly disagree}

1
2

3

4

Strongly agree

5

16. Young boys want sex as much as adult men do.

Strongly disagree

1 2

3

4 5

17. Sex must be enjoyed by both parties.

Strongly disagree

1

2

3

4

Strongly agree

18. Men need sex more than women do.

Strongly disagree

1

2

3

4

5

19. The lack of hair makes children's bodies attractive.

Strongly disagree

Strongly agree

1

2

3

Strongly agree 5 agree 
20. I have a higher sex drive than most people.

Strongly disagree

1
2

3

\section{Strongly agree}

4

5

21. Children don't tell others about sexual activity because they do not want to stop it.

Strongly disagree

1
2

3

4

5

22. I am often bothered by thoughts of having sex.

Strongly disagree

1
2

3
Strongly agree

23. A child who does not resist sexual touching really feels $\mathrm{OK}$ about being touched.

Strongly disagree

1
2

3
Strongly agree

4

5

24. If a child does not say "no", it means the child wants sex.

Strongly disagree

1
2
Strongly agree

4
5

25. A man who is denied sex suffers more than a woman who has sex when she does not want it.

Strongly disagree

1
2

3

4

Strongly agree

26. I have no trouble going without sex if my partner is not interested.

Strongly disagree

1
2
3
Strongly agree

4
5 
27. Some children are so willing to have sex that it is difficult to stay away from them.

\section{Strongly disagree}

1

2

3

4

Strongly agree

28. Young girls want sex as much as adult women do.

Strongly disagree

1
2

3
Strongly agree

4

5

29. Children are often able to understand an adult's needs better than other adults can.

Strongly disagree

1
2
Strongly agree

4

5

30. The innocent look of young girls makes them attractive.

Strongly disagree

Strongly agree

1

2

3

4

5 
Bumby's Rape Myth Acceptance Scale Scoring

\section{Scoring Instructions:}

The first nine questions of the questionnaire consists of a short version of Bumby's rape attitudes scale. This test measures cognitive distortions/deviant schema surrounding rape. Responses are summed to yield a total score. The higher the score the more cognitive distortions, justifications, and minimizations the individual has for sexual offences.

TOTAL SCORE: 145 


\section{Hanson Sex Attitude Questionnaire Short Version}

Scoring and Interpretation (20/08/99)

\section{Sexy Kids}

This scale measures the tendency to perceive children as sexually attractive and sexually motivated.

The score is the total of the following 12 items: $10,12,14,16,19,21,23,24,27,28,29$, 30 .

\section{Interpretation}

12-23 Normal range, although agreement (responses 4 or 5) to any item could indicate problem areas

24-29 Moderate deviance

30-60 Serious deviance

\section{Sexual Entitlement}

This scale measures beliefs about male sexual entitlement and the necessity of fulfilling sexual urges.

The score is calculated by summing items $11,13,15,18,20,22$ and 25 , reverse scoring items 17 and $26(5=1,4=2,3=3,2=4,5=1)$, and then adding them to other items.

\section{Interpretation}

12-21 Normal range, although agreement (responses of 4 or 5) to any item could indicate problem areas.

22-25 Moderate deviance.

26-45 Serious deviance

The above information is drawn from the following article:

Hanson, R.K., Gizzarelli, r., \& Scott, H. (1994). The attitudes of incest offenders: Sexual entitlement and acceptance of sex with children. Criminal Justice and Behavior, 21, 187 202. 
Appendix G

Informed Consent 


\section{Informed Consent Form}

The purpose of Informed Consent is to ensure that you understand the purpose of the study you are being asked to take part in, and what you will be asked to do. The Informed Consent Form must provide enough information about the study to allow you to make a reasonable decision about whether you wish to participate. Once you have read this form, you should know what the study is about, and how you can help us with it. If you have any questions, please ask the person who gave you this form.

The purpose of this study is to find out how important different types of sexual thoughts are to you. If you agree to take part in this study you will be asked to do three things: You will be asked to fill out questionnaires that ask you how you think about sex, sexual things and what you had done.

The second thing that you will be doing is a computer task. In the computer task, a word will appear on the screen. You will be asked to name the colour that the word is written in, instead of reading the word. Some of these words may be sexual words, and some may be disturbing to you. Feel free at any time to end your participation in this study. If you do not wish to continue, please inform the person that gave you this form and your participation will be ended.

Finally, you will be asked to have your FPS number kept on record in a secure and confidential place. The reason that we would like this information is in case we return to do more tests and want to ask you later to take part again.

I am being asked to take part in a study that is looking at my sexual thoughts and how important they are to me. If I agree to participate I will be filling out questionnaires that will take about 1 hour. I will also be completing a computer task where I will name the colour that a word is shown in, instead of reading the word. I will also be agreeing to have my FPS number kept on file in a secure place for future research.

If I want to stop taking part in this study at any time, I can leave without needing a good reason. All of the information that I give in the questionnaires is confidential and my personal identity will be kept secret, and will only be known by the researcher.

I understand that if anything in this study makes me feel uncomfortable or upset, I will be given the name of a psychologist that I can talk to. I also understand that my participation in this study will have no effect on my release or treatment program.

I have read the above form and with the understanding that I can stop participation at any time, I agree to participate in this study.

(If you agree to participate please sign below, and answer the questions on the following page of the form). 
1) This study will take about how long?
a) 5 minutes
b) 1 hour
c) 4 hours

2) If I do not want to finish the study, I:

a) can stop at any time

b) must finish all of the study

3) The information that I fill out:
a) will be shared
b) is confidential
c) is open to the public

Participant:

Researcher:

Date:

Date: 
Appendix $\mathrm{H}$

Debriefing 


\section{Debriefing Form}

We want to thank you very much for taking part in this study. This study is important because we think that if we can understand the thoughts of sexual offenders and views towards sex then we will be better able to target treatment and hopefully prevent them from committing similar sexual offences.

Your participation in this study was greatly needed and very much appreciated. If anything has upset you as a result of your participation in this study you can contact your institutional psychologist.

If you want more information about this study, you can contact the following people:

Shelley Price (Carleton University, sprice@ rogers.com)

Project Supervisor, Don Andrews (Carleton University)

If you have any ethical concerns, you can contact the following people:

-Chair Department of Psychology (Mary Gick, 520-2600 \#2648)

-Chair, Ethics Committee (Chris Davis, 520-2600 \#2251) 